\title{
Purification and characterization of mSin3A-containing Brg1 and hBrm chromatin remodeling complexes
}

\author{
Saïd Sif, ${ }^{1-3,5}$ Andrew J. Saurin, ${ }^{1,2}$ Anthony N. Imbalzano, ${ }^{4}$ and Robert E. Kingston ${ }^{1,2}$ \\ ${ }^{1}$ Department of Molecular Biology, Massachusetts General Hospital, Boston, Massachusetts 02114, USA; ${ }^{2}$ Department \\ of Genetics, Harvard Medical School, Boston, Massachusetts 02115, USA; ${ }^{3}$ Department of Molecular and Cellular \\ Biochemistry, Ohio State University College of Medicine, Columbus, Ohio 43210, USA; ${ }^{4}$ Department of Cell Biology, \\ University of Massachusetts Medical School, Worcester, Massachusetts 01655, USA
}

\begin{abstract}
Alteration of nucleosomes by ATP-dependent remodeling complexes represents a critical step in the regulation of transcription. The human SWI/SNF (hSWI/SNF) family is composed of complexes that contain either Brg1 or hBrm as the central ATPase; however, these separate complexes have not been compared functionally. Here we describe the establishment of cell lines that express epitope-tagged Brg1 and hBrm and a characterization of the complexes associated with these two ATPases. We show that Brg1 fractionates into two complexes that differ in activity and subunit composition, whereas $\mathrm{hBrm}$ is found in one complex with lower activity than the Brg1 complexes. These three complexes can remodel nucleosomal arrays, increase restriction enzyme accessibility, and hydrolyze ATP in a DNA-dependent manner. The three complexes differ markedly in their ability to remodel mononucleosomal core particles. We also show that the hBrm complex and one of the Brg1 complexes contain components of the mammalian $\operatorname{Sin} 3(\mathrm{mSin} 3)$ complex. In addition, we have found that Brg1, hBrm, and BAF155 can interact specifically with mSin3A in vitro, showing a direct association of hSWI/SNF complexes with proteins involved in gene repression. These unexpected functional characteristics indicate that these hSWI/SNF complexes play diverse regulatory roles.
\end{abstract}

[Key Words: Chromatin remodeling; ATPase activity; histone deacetylases; Sin3 repressor complex; human SWI/SNF complexes]

Received December 11, 2000; revised version accepted January 16, 2001.

The mechanisms by which genomic DNA is packaged into chromatin and is unwound during precise stages of cell growth and development have remained obscure. However, with the discovery of chromatin remodelers, histone acetyl-transferases and deacetylases, and DNA methylases and demethylases, it has become clear that cells use a variety of cellular machines to establish and maintain various programs of gene expression (for reviews, see Bird and Wolffe 1999; Kingston and Narlikar 1999; Knoepfler and Eisenman 1999; Kouzarides 1999; Wolffe et al. 1999). Among the activities that facilitate the transition of chromatin from a closed to a more open conformation are multisubunit complexes that use the energy of ATP to alter nucleosome structure. All chromatin remodeling complexes contain a central ATPase that has homology with the yeast SWI2/SNF2. There are three types of ATPases that can be grouped into different subfamilies depending on whether they contain either a bromodomain (SWI2/SNF2 subfamily), two copies of a

${ }^{5}$ Corresponding author.

E-MAIL Sif.1@osu.edu; FAX (614) 292-4118.

Article and publication are at www.genesdev.org/cgi/doi/10.1101/ $\operatorname{gad} .872801$. chromodomain (Mi-2/CHD subfamily), or lack both domains (ISWI subfamily) (Eisen et al. 1995). Members of all three subfamilies have been shown to be part of multisubunit complexes that can remodel nucleosomes in an ATP-dependent manner and either enhance or alleviate the repressive effects of chromatin (for review, see Vignali et al. 2000).

In humans all chromatin remodelers purified to date contain different subunits, except the Brgl and hBrm complexes, which have been shown to share several highly conserved subunits (Kwon et al. 1994; Wang et al. 1996a,b; Sif et al. 1998). Some of the shared subunits, such as p155 and p170, which are the homologs of yeast SWI3, have been shown to be highly related to each other (Wang et al. 1996b). In addition, three splice variants of p60, which is the human homolog of yeast SWP73, have been shown to be expressed in a tissue-specific manner and are part of different remodeling complexes (Wang et al. 1996b). This heterogeneity of the Brgl and hBrm complexes has been proposed to be growth and developmentally relevant. The theme of similarity between subunits has also been found in the case of human nucleosome remodeling and deacetylase complex (NuRD), which contains Mi-2 as its central ATPase. NuRD also contains 
subunits that are highly related to each other, which include histone deacetylases (HDACs) 1 and 2 and retinoblastoma associated proteins (RbA) p46 and p48 (Tong et al. 1998; Wade et al. 1998; Xue et al. 1998; Zhang et al. 1998a). Presently, it is not clear why there are subunits that are highly related within each complex.

The second type of modification that has been shown to play an important role in the regulation of transcription and to have an effect on nucleosome stability is histone acetylation and deacetylation. Modification of histones by acetylation has been linked to gene activation, whereas histone deacetylation has been correlated with gene repression and silencing (for review, see Grunstein 1997). Recent studies have shown that HDAC1 and 2 can associate with mammalian homologs of the yeast corepressor Sin3, mSin3A and B (Alland et al. 1997; Hassig et al. 1997; Laherty et al. 1997; Nagy et al. 1997). This Sin3-histone deacetylase complex also contains RbAp46 and $\mathrm{RbAp} 48$, as well as the mSin3A-associated proteins, SAP18 and SAP30, whose functions are unknown (Zhang et al. 1997; Zhang et al. 1998b). Several reports have shown that the Sin 3 complex can be targeted by specific transcription factors to repress gene expression. Therefore, it was proposed that repression can be achieved by recruiting histone deacetylase activity to specific promoters. However, it was not clear how HDACs might function in the context of chromatin. Purification of NuRD, which lacks mSin3A subunits, provided the first link between histone deacetylation and chromatin remodeling (Tong et al. 1998; Xue et al. 1998; Zhang et al. 1998a). This finding indicated that repressor proteins can inhibit transcription by targeting complexes with dual function, which can both alter nucleosome structure and deacetylate histones.

To begin to understand some of the biological properties of $\mathrm{Brg} 1$ and hBrm, we have examined the activity of these two ATPases across the cell cycle and found that they are regulated differently by phosphorylation during mitosis (Muchardt et al. 1996; Sif et al. 1998). Furthermore, $\mathrm{Brg} 1$ and $\mathrm{hBrm}$ have been implicated in the control of cell growth and proliferation through their interaction with the $\mathrm{Rb}$ family of tumor suppressor proteins (Dunaief et al. 1994; Strober et al. 1996; Zhang et al. 2000). Brgl has also been shown to be involved in the repression of the c-fos gene through a pathway that is $\mathrm{Rb}$-dependent (Murphy et al. 1999). These results were surprising because Brgl and hBrm have been shown previously to be able to stimulate transcriptional activation by various transcription factors (Muchardt and Yaniv 1993; Chiba et al. 1994; Singh et al. 1995). Taken together, these results indicate that although Brgl and hBrm are highly related and interact with similar subunits, their activities are regulated and targeted differently.

To shed more light on the subunit composition as well as the chromatin remodeling activity of the Brg1 and hBrm complexes, we have established cell lines that express either Flag-tagged Brgl or hBrm. We report that there are two forms of the Brgl complex that differ by their subunit composition and that can remodel chromatin more efficiently than the hBrm complex. We also present evidence that the Brg1 and hBrm complexes contain subunits of the human Sin 3 complex. These differences in mechanism, composition, and associated proteins are likely to be important for the ability of Brgl and $\mathrm{hBrm}$ complexes to participate in both activation and repression of transcription.

\section{Results \\ Purification of Flag-tagged Brg1-and hBrm-based chromatin remodeling complexes}

We have reported previously that we can isolate endogenous Brgl- and hBrm-based chromatin remodeling complexes using a two-step purification scheme (Sif et al. 1998). However, using various purification strategies, we have been unable to separate the Brgl and hBrm complexes (Kwon et al. 1994; data not shown). To separate these two complexes, we created cell lines that express either Flag-tagged Brgl or hBrm. Nuclear extracts from these cell lines were incubated with anti-Flag M2 affinity gel, and after several washes with buffer containing increasing salt concentrations, the proteins retained on the column were eluted with buffer containing Flag peptide (Fig. 1A). Analysis of equal amounts of wild-type and mutant Fl-Brgl and Fl-hBrm fractions by SDS-PAGE and silver staining showed that they contain several prominent bands of the same size as the hSWI/SNF subunits (arrows, Fig. 1B, lanes 2-4). For comparison, Brg1 and $\mathrm{hBrm}$ complexes purified through the Inil subunit are shown (Fig. 1B, lane 1). Approximately 144 ng of each fraction was also analyzed by Western blotting using anti-Flag antibodies (Fig. 1C). There were similar amounts of epitope-tagged mutant and wild-type $\operatorname{Brg} 1$ as well as hBrm in the affinity-purified fractions (lanes 2-4), indicating that the concentration of the complexes that contain these proteins is similar in each fraction. Using antibodies specific to cloned hSWI/SNF subunits, we were able to determine that the Fl-Brgl and Fl-hBrm complexes contain common subunits such as p155 and p60 (Fig. 1C, lanes 5-8).

Previously, endogenous Brgl and hBrm have been shown to exist in two distinct complexes (Wang et al. 1996b). Therefore, we wished to determine whether FlBrgl and Fl-hBrm can be found in the same complex. We used specific antibodies to show that Fl-Brgl and Fl$\mathrm{hBrm}$ reside in two separate complexes when isolated from the epitope-tagged cell lines (Fig. 1C, cf. lanes 6 and 7 with lane 8).

\section{Affinity-purified Fl-Brg1 and Fl-hBrm fractions contain subunits of the human Sin3 complex}

We noted that there were additional proteins associated with both the Fl-hBrm and Fl-Brg1 immunopurified complexes. We used antibodies to test these fractions for a wide variety of proteins that modify chromatin structure (see below). Surprisingly, we found that mSin3A, HDAC1, HDAC2, and RbAp48 all copurified with Fl- 


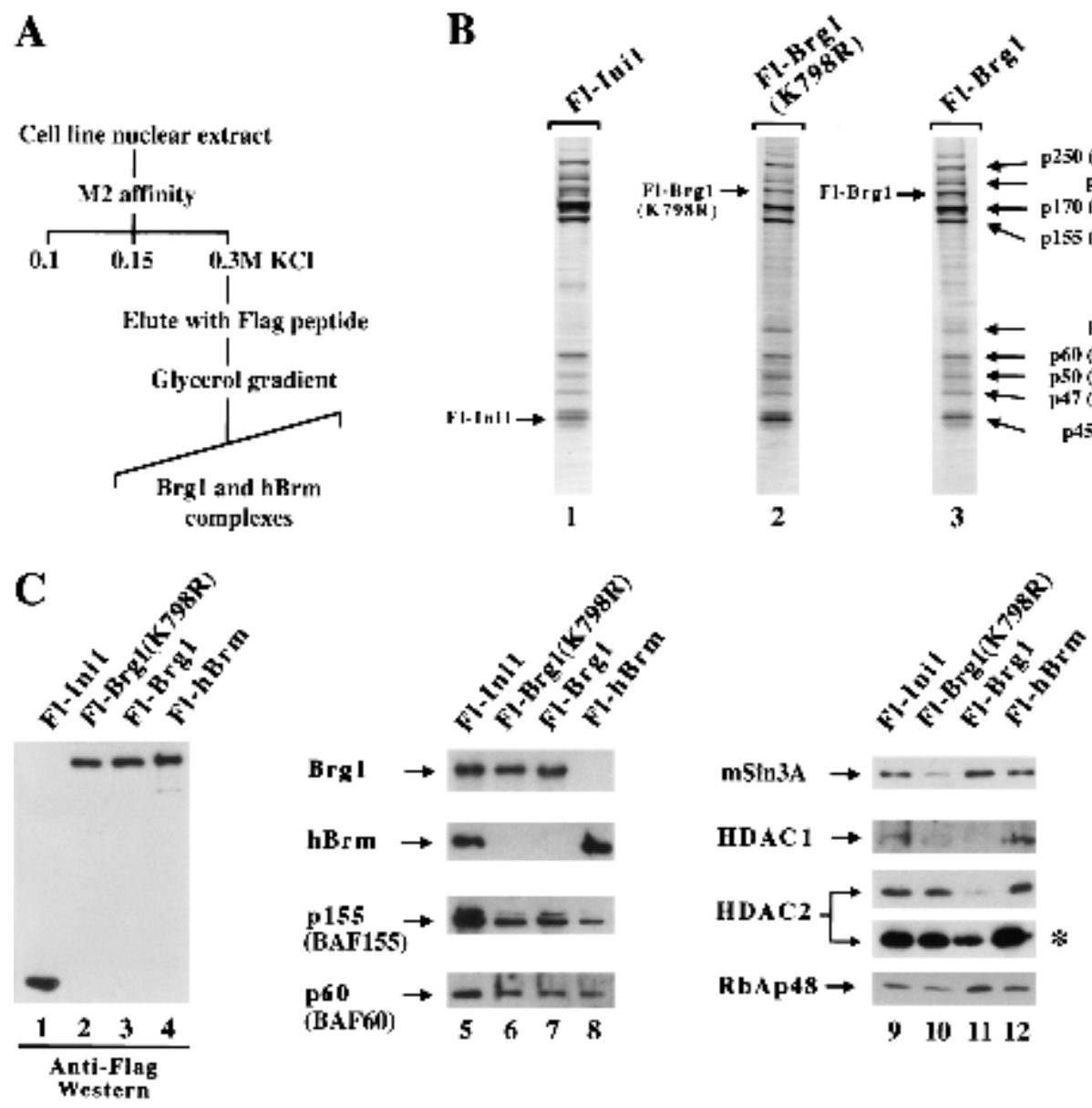
sociated with Fl-Inil, wild-type and mutant Fl-Brg1, and Fl-hBrm. (A) Scheme for purification of Brg1 and hBrm complexes. See Materials and Methods for details. (B) SDS-PAGE analysis of Brg1 and hBrm complexes. Approximately $144 \mathrm{ng}$ of affinity-purified fractions from cell lines that express Fl-Ini1 (lane 1), mutant Fl-Brg1 (lane 2), wild-type Fl-Brg1 (lane 3) and Fl-hBrm (lane 4) were analyzed by SDS-PAGE, and the proteins were visualized by silver staining. (Arrows) Shared subunits; (horizontal bars alongside the hBrm gell novel subunits. $(C)$ Brgl and hBrm fractions contain components of the human Sin3 complex. The same amounts of proteins analyzed by silver staining were analyzed by Western blotting using affinity-purified complexes from Fl-Ini1, which contain endogenous Brg1 and hBrm (lanes 1,5,9), mutant Fl-Brg1 (lanes 2,6,10), wild-type Fl-Brg1 (lanes 3,7,11), and Fl-hBrm (lanes 4,8,12). (Asterisk) Long exposure of the HDAC2 Western blot.

hBrm (Fig. 1C, lane 12). All of these subunits have been shown previously to coexist in the human Sin3 histone deacetylase complex, which has been implicated in the repression of transcription. Affinity-purified Fl-Brgl fractions contained $\mathrm{mSin} 3 \mathrm{~A}, \mathrm{HDAC} 2$, and $\mathrm{RbAp} 48$, but did not contain detectable levels of HDAC1 (Fig. 1C, lane 11). Mutant Fl-Brg1 fractions contained the same set of proteins; however, their ratios appear to be different (Fig. $1 \mathrm{C}$, cf. lanes 10 and 11). We also determined that HDAC3, Mi-2 $\alpha$ (CHD3), and Mi-2 $\beta$ (CHD4) were not present in the affinity-purified hSWI/SNF complexes (data not shown), indicating that the association of mSin3A, HDAC1, and HDAC2 with Brgl and hBrm complexes is specific.

\section{Fl-Brg1- and Fl-hBrm-based chromatin remodeling complexes are functionally different}

Brg1 and hBrm complexes were purified previously; however, their ability to remodel chromatin individually has not been tested. Therefore, we wanted to measure and compare the chromatin remodeling activity of these complexes by testing their ability to disrupt nucleosomal core particles. We titrated equivalent amounts of affinity-purified Fl-Brgl and Fl-hBrm complexes into reactions that contained labeled mononucleosomes. The Fl-Brgl fractions caused an ATP-dependent change in the DNase I digestion pattern (Fig. 2A, lanes 16-21). In contrast, when equal amounts of Fl-hBrm fractions were incubated with core nucleosomes in the presence of ATP, there was no noticeable change in cutting by DNase I (Fig. 2A, lanes 22-27). As a control, fractions containing $\mathrm{Brg} 1$ and $\mathrm{hBrm}$ complexes purified through the Inil subunit (Fig. 2A, lanes 4-9), or mutant Fl-Brgl (K798R), which is unable to bind ATP (lanes 10-15), are shown.

All SWI/SNF related complexes that have been studied have a DNA-stimulated ATPase activity. Therefore, we measured the ability of the Fl-Brgl and Fl-hBrm complexes to hydrolyze ATP both in the presence and absence of DNA using equal amounts of protein (Fig. 2B). Under saturating conditions of ATP and DNA, the ATPase activity of affinity-purified Fl-Brg1, Fl-Inil, and Fl-hBrm complexes was stimulated fourfold by DNA relative to ATPase activity in the absence of DNA. In contrast, affinity-purified Fl-Brg1 (K798R), which cannot 
Sif et al.

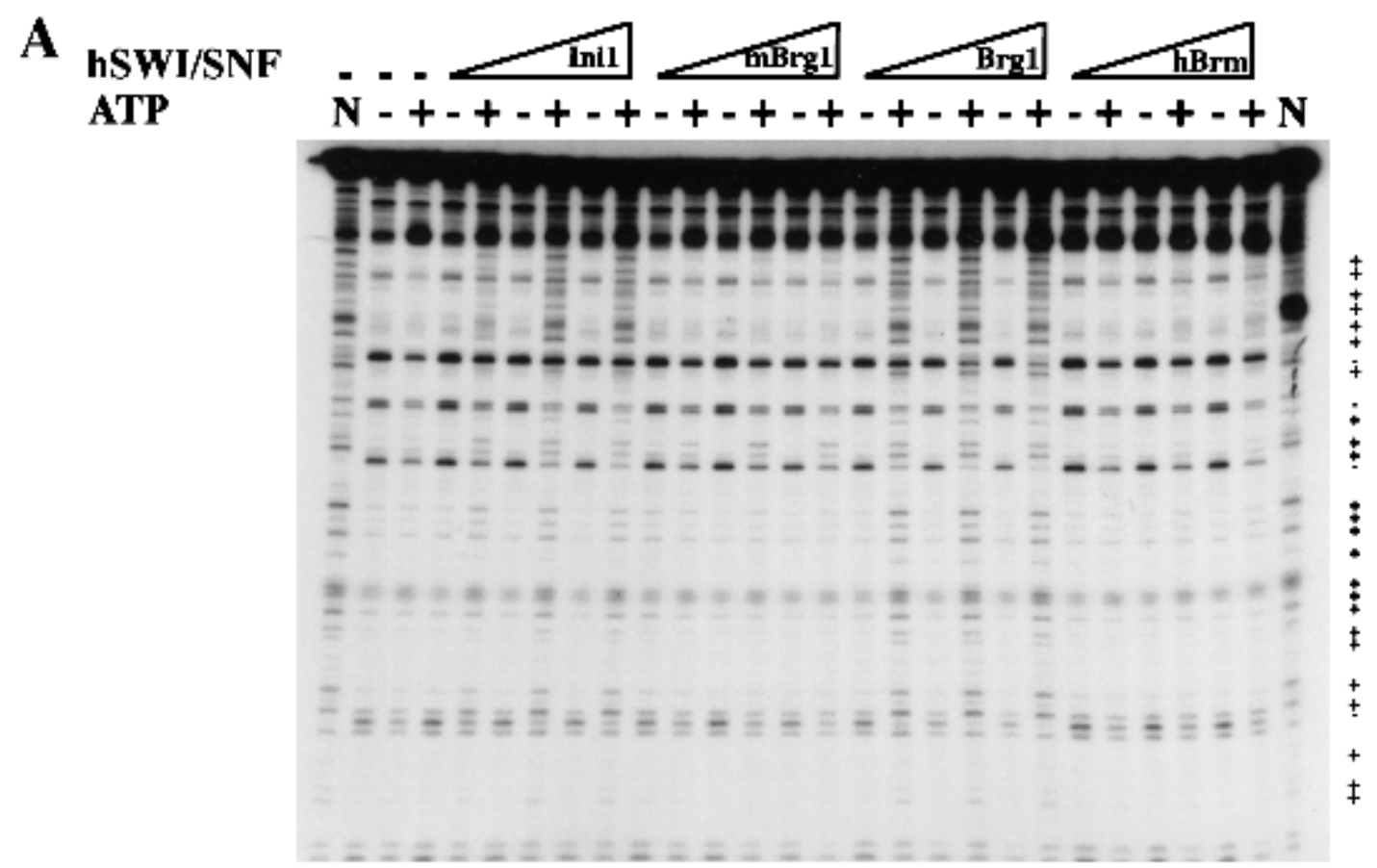

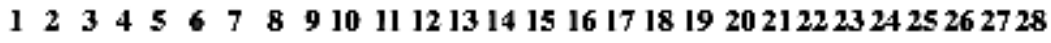

B

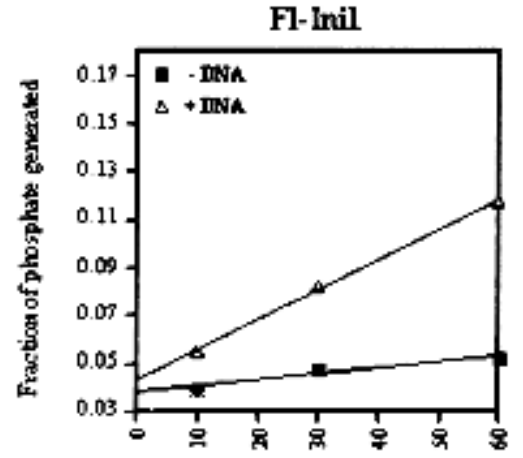

F1-Brgl (K798R)

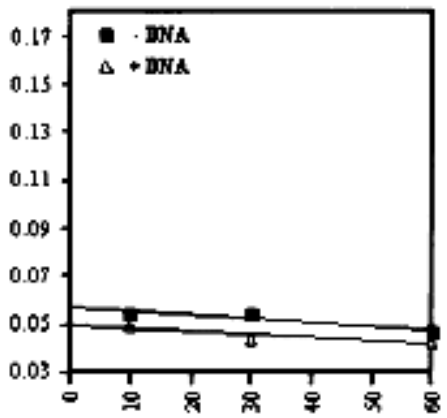

Fl-Brgl

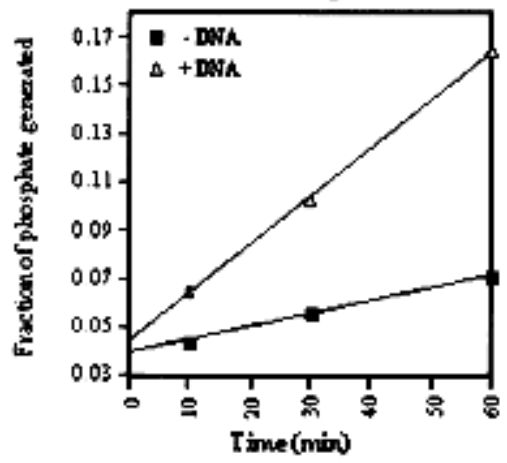

F-hBrm

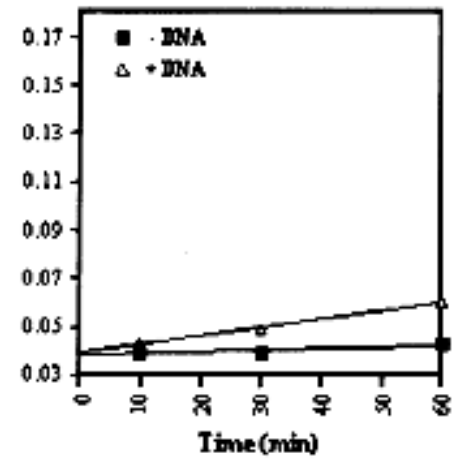

Figure 2. Biochemical characterization of Flag-tagged Brgl and hBrm complexes. (A) Mononucleosome disruption by Brg1 and hBrm complexes. Equal amounts of affinity-purified fractions (in twofold increments from $36 \mathrm{ng}[0.72 \mathrm{nM}]$ to $144 \mathrm{ng}$ [2.88 $\mathrm{nM}]$ ) containing either Fl-Inil complexes (lanes 4-9), mutant Fl-Brg1 (lanes 10-15), wild-type Fl-Brg1 (lanes 16-21), or Fl-hBrm (lanes 22-27) were incubated with nucleosome cores with or without ATP as indicated. As a control, naked DNA (N, lanes 1,28) and nucleosome cores with and without ATP (lanes 2,3) are shown. (+) Increased DNase I cleavage; (-) decreased DNase I cleavage. (B) ATPase activity of immunopurified Brg1 and hBrm complexes. Approximately $72 \mathrm{ng}(3.6 \mathrm{nM})$ of either Fl-Inil, mutant Fl-Brg1 (K798R), wild-type Fl-Brg1, or Fl-hBrm was incubated with $20 \mathrm{nM}$ naked plasmid DNA and $\left[\gamma_{-}{ }^{32} \mathrm{P}\right] \mathrm{ATP}$ for the indicated times. The phosphate present at time zero is due to the presence of $\left[\gamma^{-}{ }^{32} \mathrm{P}\right]$ phosphate in the $\left[\gamma^{-32} \mathrm{P}\right]$ ATP stock. The ratio of inorganic phosphate to ATP was quantitated for each time point using a Molecular Dynamics PhosphorImager. 
bind ATP, was catalytically inactive. When we compared the DNA-stimulated rate of ATP hydrolysis, we found that Fl-Brgl complexes have a 1.5- and 5-fold higher specific activity than the complexes purified through the Inil and hBrm, respectively.

Because the fractions that contain Fl-hBrm appear to hydrolyze ATP but were unable to remodel mononucleosomes, we tested their ability to remodel chromatin using polynucleosomal templates. First, we tested the ability of affinity-purified Fl-Brgl and Fl-hBrm complexes to alter the topology of plasmid DNA that has been assembled into arrays of nucleosomes using Drosophila S190 extracts (Fig. 3A). When equal amounts of affinity-purified Fl-Brg1 and Fl-hBrm fractions were incubated with highly negatively supercoiled plasmid DNA in the absence of ATP, there was no change in topology of the DNA templates (Fig. 3A, lanes $7,9)$. However, when ATP was added to the reactions, Fl-Brgl and Fl-hBrm complexes were able to remodel as shown by the increase in the amount of slowly migrating DNA species that contain fewer negative supercoils (Fig. 3A, cf. lanes 8 and 10 with lane 2). For comparison, fractions that contain a mixture of endogenous Brg1 and hBrm, or mutant Fl-Brg1 (K798R), which is catalytically inactive, are shown (Fig. 3A, lanes 3-6). In agreement with the ATPase assay, these results show that the Fl-hBrm complex can hydrolyze ATP and remodel chromatin.

To rule out the possibility that there are additional factors in the Drosophila S190 extracts that might assist Fl-hBrm complexes in remodeling chromatin templates, we also tested Fl-Brgl and Fl-hBrm complexes for their ability to remodel a linear DNA template that was assembled using purified components. The DNA fragment used in this assay contains an array of 12 nucleosomes. The middle two nucleosomes include unique restriction sites that are located either within the nucleosome (Fig. 3B, HhaI and XbaI sites) or in the linker region between nucleosomes (SacI site) (Neely et al. 1999). The assembly of this template was achieved by salt dialysis using purified DNA and H1-depleted HeLa core histones. The nucleosomal phasing was determined by restriction enzyme cutting (see below) and MNase/Southern blotting (Fig. 3B).
$\mathbf{A}$

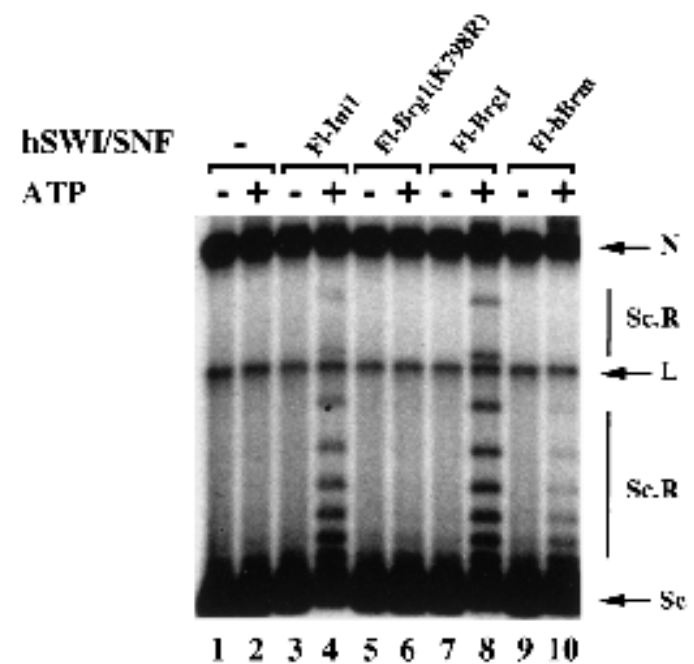

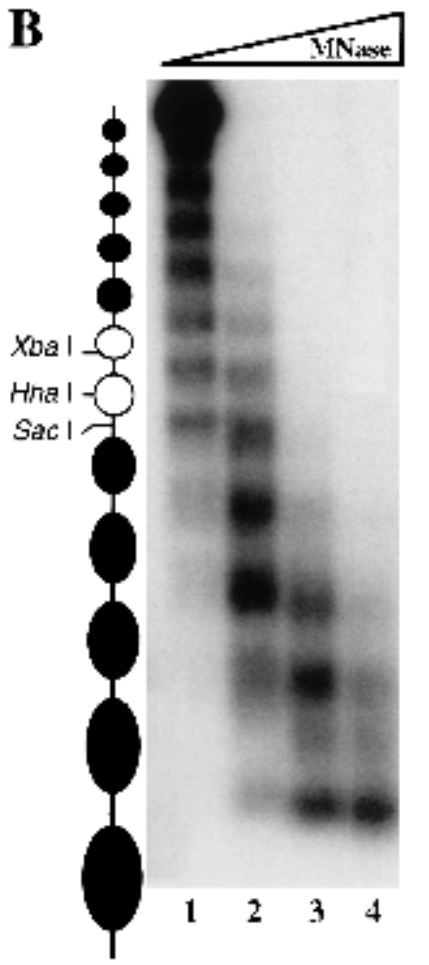

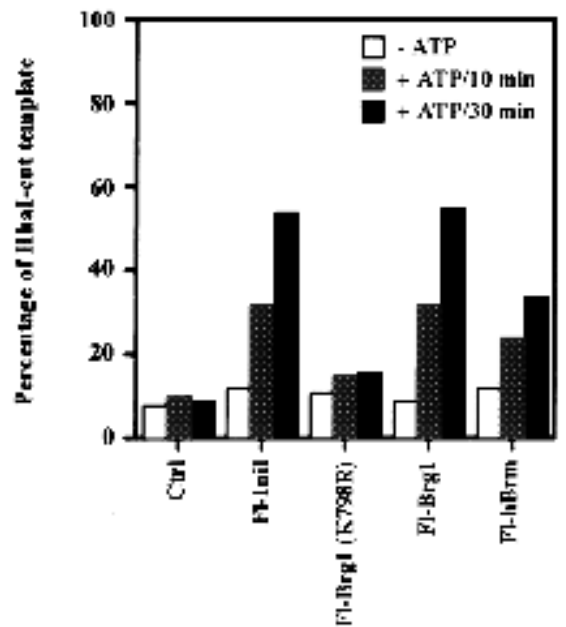

Figure 3. Disruption of polynucleosomal templates. (A) Brgl and hBrm complexes can alter the topology of highly negatively supercoiled chromatin templates. Approximately $144 \mathrm{ng}(2.88 \mathrm{nM})$ of affinity-purified Fl-Inil complexes (lanes 3,4), mutant Fl-Brg1 (lanes 5,6), wild-type Fl-Brg1 (lanes 7,8), and Fl-hBrm (lanes 9,10) was incubated with nucleosome-assembled plasmid DNA in the absence or presence of ATP as indicated. (Lanes 1,2) Assembled templates without Brgl and hBrm complexes. (N) Nicked closed circular DNA; (L) linear DNA; (Sc) supercoiled DNA; (Sc.R) less supercoiled and relaxed DNA. (B) Analysis of the 5S polynucleosomal array. To determine the extent of assembly of the $5 \mathrm{~S}$ array, increasing amounts of MNase (lane 1, $1 \mathrm{mU} ;$ lane 2, $10 \mathrm{mU}$; lane 3, 100 $\mathrm{mU}$; lane 4, 1U) were added to $2 \mathrm{ng}$ of assembled template, and the 5S DNA was detected by Southern blotting as described in Materials and Methods. $(C)$ Brgl and hBrm complexes can increase restriction enzyme accessibility. Equal amounts (144 ng, or $2.88 \mathrm{nM}$ ) of affinity-purified Brgl and hBrm complexes were incubated with $6 \mathrm{ng}(0.14 \mathrm{nM})$ of $5 \mathrm{~S}$ nucleosomal arrays. After either 10 or 30 min at $30^{\circ} \mathrm{C}$, HhaI was added, and the reactions were incubated for an additional $60 \mathrm{~min}$ at $30^{\circ} \mathrm{C}$. The percentage of $H$ haI-cut template represents the ratio of cut DNA to total amount of template. 
In this assay, the chromatin remodeling activity is measured by the ability of the immunopurified complexes to either increase or decrease accessibility to restriction enzyme sites. When equal amounts of Fl-Brg1 and Fl-hBrm complexes were incubated with the 5S array and accessibility to the otherwise occluded HhaI site was measured by incubating the template with restriction enzyme, we were able to see an increase in cutting only in the presence of ATP (Fig. 3C). Similar results were obtained when $\mathrm{XbaI}$ was used (data not shown). Quantification of the amount of template digested by HhaI after $30 \mathrm{~min}$ of chromatin remodeling revealed that the Fl-Brg1 complexes increased cutting by 6.9-fold, whereas the Fl-hBrm complex caused a 4.3-fold increase. Furthermore, when the Inil fractions were tested in this assay, there was a 6.8 -fold stimulation of cutting by HhaI. Mutant Fl-Brg1 (K798R), which lacks ATPase activity, showed a twofold stimulation; there is no activity of this fraction following further purification (see below). We have also tested the ability of wild-type and mutant Fl-Brg1, Fl-hBrm, and Fl-Inil complexes to remodel 5S arrays using substoichiometric amounts of hSWI/SNF proteins and obtained similar results (data not shown). We conclude that the Fl-hBrm complexes have a 1.6-fold lower specific activity than the Fl-Brgl complexes in the protocol that measures remodeling of arrays, but that there is a much more significant decrease in the relative ability of the Fl-Brm complex to remodel mononucleosomes.

\section{Components of the Sin3 complex cofractionate} with the Brg1 and hBrm complexes

Affinity-purified Brgl and hBrm fractions contain subunits of the Sin3 complex (Fig. 1C). To determine whether these subunits cofractionate with Brgl and hBrm, we separated equivalent amounts of each complex using a glycerol gradient and analyzed each fraction by silver staining and Western blot analysis (Figs. 4,5). Fractionation of wild-type and mutant Fl-Brg1 complexes followed by silver stain analysis revealed two different types of complexes (labeled I and II, Fig. 4A,C). We show below that the location of these two peaks correlates with two different peaks of remodeling activity. Wildtype Fl-Brg1 complex I elutes in fractions 8 through 12, and complex II, which lacks the $50-\mathrm{kD}$ subunit, and the 60-kD and 220-kD doublets, elutes in fractions 13 through 17 (Fig. 4A). The wild-type and mutant Fl-Brg1 complexes have similar polypeptide banding patterns (Fig. 4C). By Western blotting, Brgl was present in complexes I and II; however, the mSin3A subunit was found only in complex I (Fig. 4B, fractions 9-11 and Fig. 4D, fractions 7-10). HDAC2 was detected in most fractions of mutant Fl-Brg1 (K798R), and was hardly detectable in the wild-type fractions because its levels were reduced relative to the Fl-Ini1, mutant Fl-Brg1, and Fl-hBrm fractions (Fig. 1C, lanes 9-12).

There are at least two types of complexes in the affinity-purified Fl-Inil fractions, which differ by their subunit composition (Fig. 5A). The first type of complex coincides with the peak of anti-Brg1 and anti-hBrm activity (Fig. 5B, fractions 8-11), whereas complex II appears to lack the subunits that migrate as 60 - and $220-\mathrm{kD}$ doublets and contains substoichiometric amounts of the 47-kD subunit (Fig. 5A). There are also complexes that lack the upper high molecular weight subunits (Fig. 5B, fractions 15-19). Western blot analysis of the glycerol gradient fractions revealed that endogenous Brgl and hBrm cofractionate in the complexes isolated using tagged Ini1 (Fig. 5B, fractions 9-11). HDAC1 and mSin3A cofractionate with the peak of Brgl and hBrm complexes (fraction 10, and data not shown). HDAC2 was also detected in these gradient fractions; however, its elution profile appeared to be more widespread than the other components of the Sin3 complex.

Analysis of Fl-hBrm fractions showed that there is only one major complex that elutes in fractions 9 through 11 and correlates with the activity of anti-FlhBrm antibodies (Fig. 5C,D). This complex also correlates with the presence of remodeling activity (see below). By Western blotting, it appears that $\mathrm{mSin} 3 \mathrm{~A}$, HDAC1, and HDAC2 cofractionate with Fl-hBrm and its associated hSWI/SNF subunits (Fig. 5C,D). It is important to note that unlike Fl-Brg1, which is found in at least two different complexes that appear to lack HDAC1 and have reduced levels of HDAC2 (Fig. 4B), Fl-hBrm is found in only one complex and is associated with both HDAC1 and HDAC2 (Fig. 5D). Furthermore, by silver staining it appears that the Fl-hBrm complex lacks only the 220-kD doublet (Fig. 5C, fractions 9-11). Taken together, these results show that although Fl-Brg1 and Fl-hBrm complexes contain highly conserved subunits, they interact differently with other proteins, and consequently this might affect their ability to remodel chromatin.

We have found that mSin3A cofractionates with Brg1 and with hBrm in all four cell lines that we have analyzed. In addition, there are Brg1 complexes that have remodeling activity but do not associate with $\mathrm{mSin} 3 \mathrm{~A}$ (complex II). Therefore, we conclude that there is a direct association of $\mathrm{mSin} 3 \mathrm{~A}$, which is normally involved in gene repression, with specific Brgl- and hBrm-based chromatin remodeling complexes.

\section{Interaction of $m \operatorname{Sin} 3 A$ with hSWI/SNF subunits} in vitro

To further study which components of hSWI/SNF complexes mediate the interaction with the Sin3A complex, we performed immunoprecipitation experiments using in vitro translated proteins. Fl-Brg1, Fl-hBrm, BAF155, BAF60, and Fl-Inil were expressed either individually (Fig. 6A, lanes 1-5) or in combination with mSin3A (Fig. $6 \mathrm{~A}$, lanes $7-11)$ in the presence of $\left[{ }^{35} \mathrm{~S}\right]$ methionine and were subjected to immunoprecipitation with an affinitypurified anti-mSin3A antibody (Fig. 6B, lanes 7-11). After extensive washing of the immunoprecipitates, hSWI/ SNF subunits that interacted with $\mathrm{mSin} 3 \mathrm{~A}$ were released by heat denaturation and subjected to a second immunoprecipitation using specific antibodies. Fl-Brg1, 

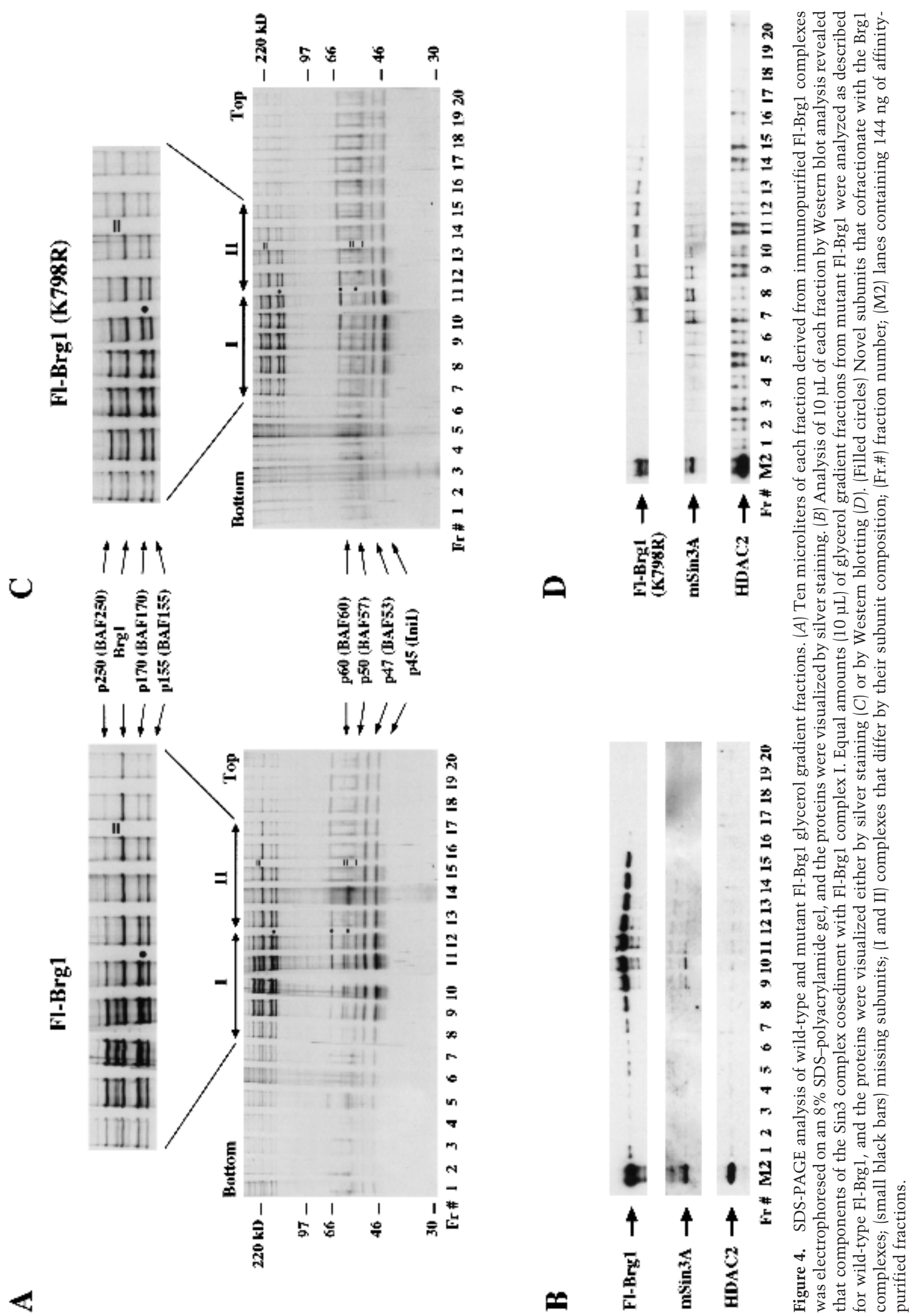


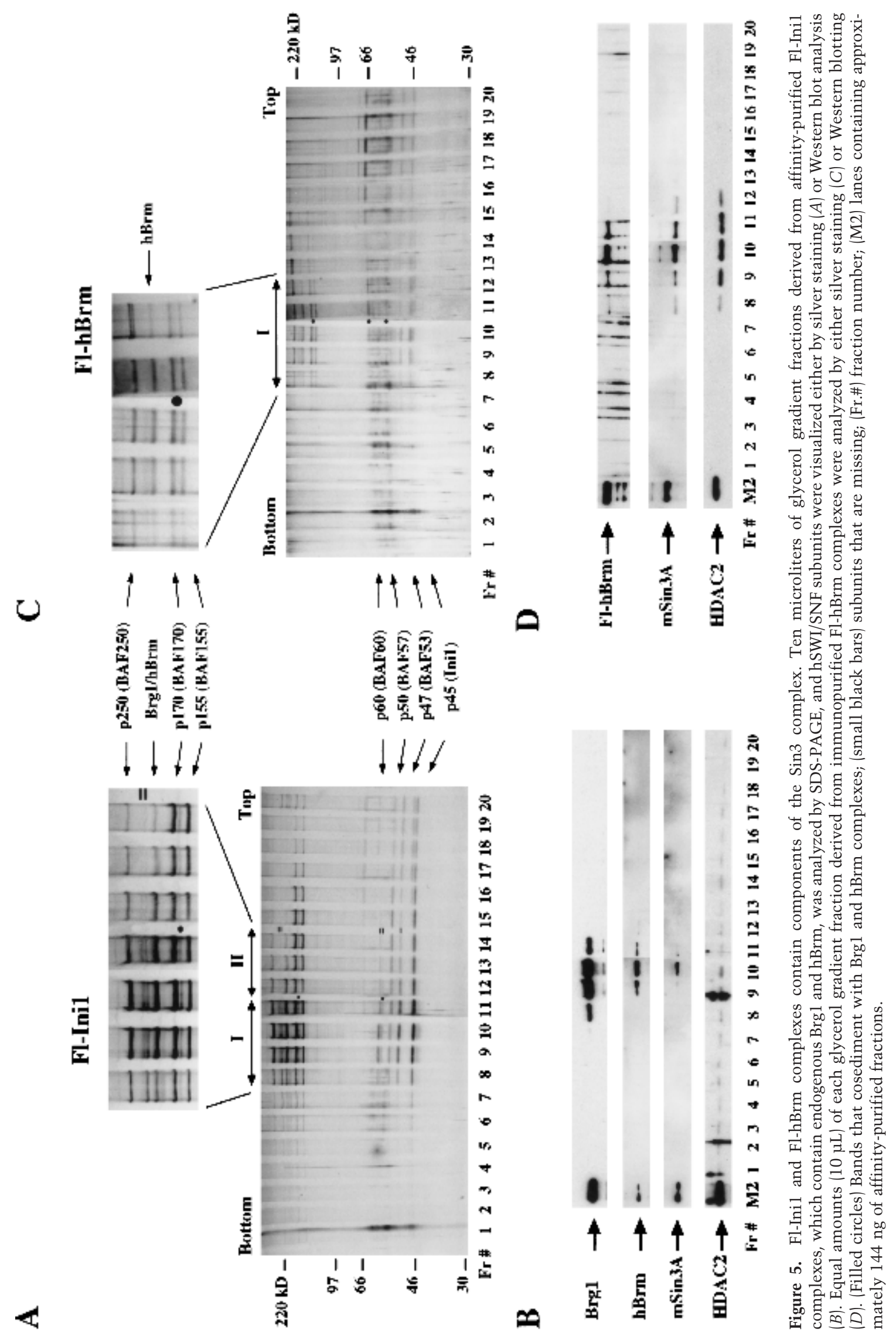


A

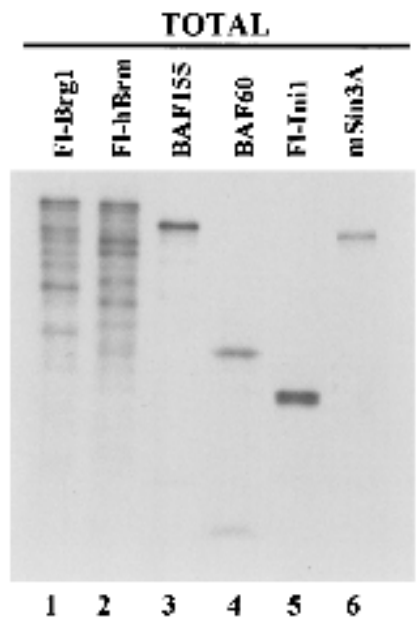

B

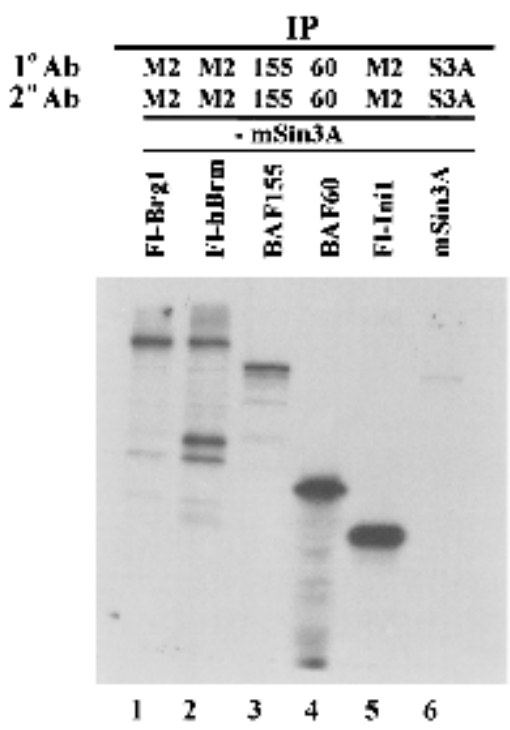

TOTAL
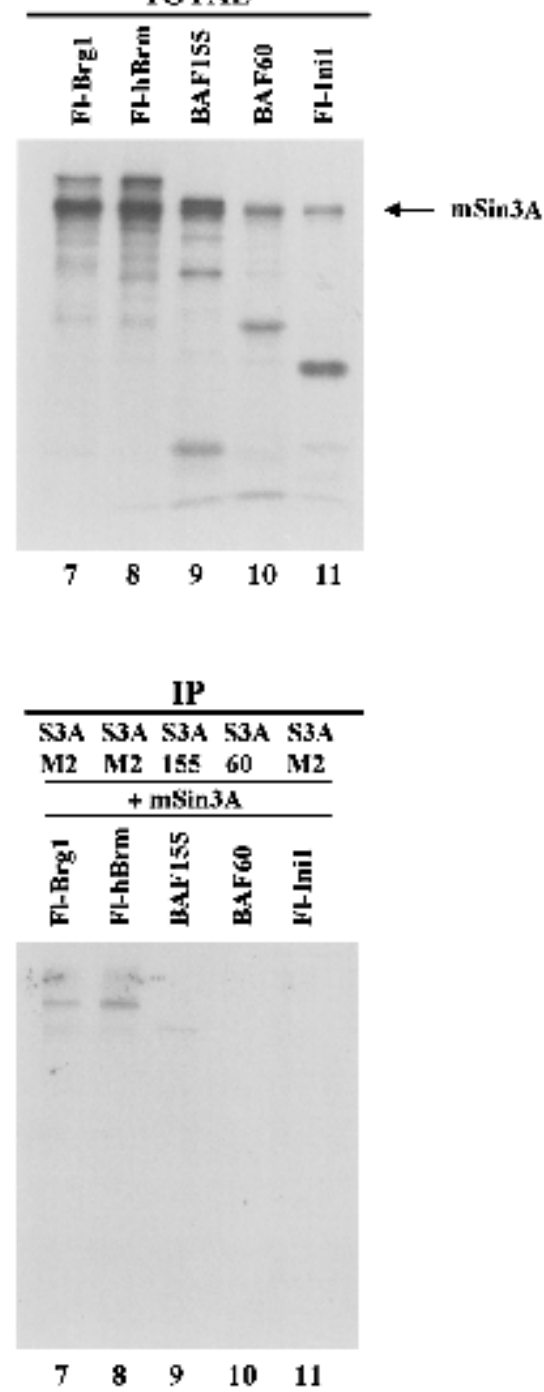

Figure 6. $\mathrm{mSin} 3 \mathrm{~A}$ can associate specifically with hSWI/SNF subunits in vitro. $(A)$ hSWI/SNF subunits were in vitro translated either individually (lanes 1-5) or in combination with $\mathrm{mSin} 3 \mathrm{~A}$ (lanes 7-11) using the Promega TNT coupled reticulocyte lysate system as described in Materials and Methods. TOTAL represents $33 \%$ of the total amount of protein used in the immunoprecipitation assays. (B) Individual proteins that were immunoprecipitated (IP) (lanes 1-6) were first immunoprecipitated $\left(1^{\circ} \mathrm{Ab}\right)$ with either anti-Flag (M2), anti-BAF155 (155), anti-BAF60 (60), or anti-mSin3A (S3A) antibodies and then subjected to a second immunoprecipitation $\left(2^{\circ} \mathrm{Ab}\right)$ as indicated. (Lanes 7-11) Double immunoprecipitations of hSWI/SNF subunits that were cotranslated with $\mathrm{mSin} 3 \mathrm{~A}$.
F-hBrm, and BAF155 were the only hSWI/SNF subunits detected, indicating that these subunits can interact with mSin3A. As a control, immunoprecipitations of individually translated proteins are shown (Fig. 6B, lanes 1-6). When preimmune anti-Brgl, anti-hBrm, and antiBAF155 antisera were used, no labeled proteins were detected (data not shown). In light of these results, we conclude that the association of $\mathrm{mSin} 3 \mathrm{~A}$ with the Brg1 and $\mathrm{hBrm}$ complexes is specific.

\section{Brg1 complexes fractionate into two functionally distinct complexes on glycerol gradients}

To characterize further the function of the Brg1 and hBrm complexes in chromatin remodeling, we separated equal amounts of these complexes using glycerol gradient sedimentation and tested the resultant fractions for remodeling activity. We assayed each fraction for its ability to disrupt the DNase I digestion pattern of mono- nucleosomes in the presence of ATP, and we also tested the ability of each fraction to enhance restriction enzyme access to a $5 \mathrm{~S}$ nucleosomal array. We were surprised to find two different peaks of activity when we fractionated the affinity-purified Brgl complexes (Fig. 7A,B, Fl-Brg1 panels). In the mononucleosome remodeling assay, fractions 9-11 displayed strong disruption of the DNase I digestion pattern in regions that correspond to the shoulder of the nucleosome, but showed less disruption near the dyad axis. In contrast, fractions 13-16 showed disruption of the DNase I digestion pattern throughout the mononucleosome. When these fractions were tested for activity on nucleosomal arrays using the restriction enzyme cleavage protocol, we found maximal activities in fractions 9 through 16 (Fig. 7C). Although all active fractions contain Brgl (Fig. 4B), there are differences in associated proteins that correlate with the differences in the mononucleosome disruption assay. In all assays, mutant Fl-Brg1 complexes had no activity (Fig. 
Sif et al.

$\mathbf{A}$

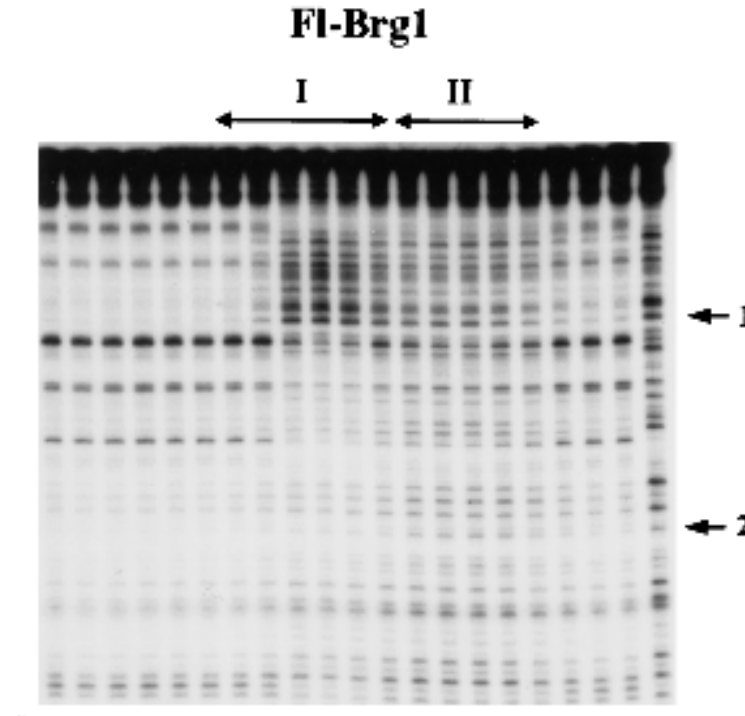

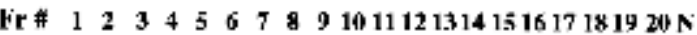

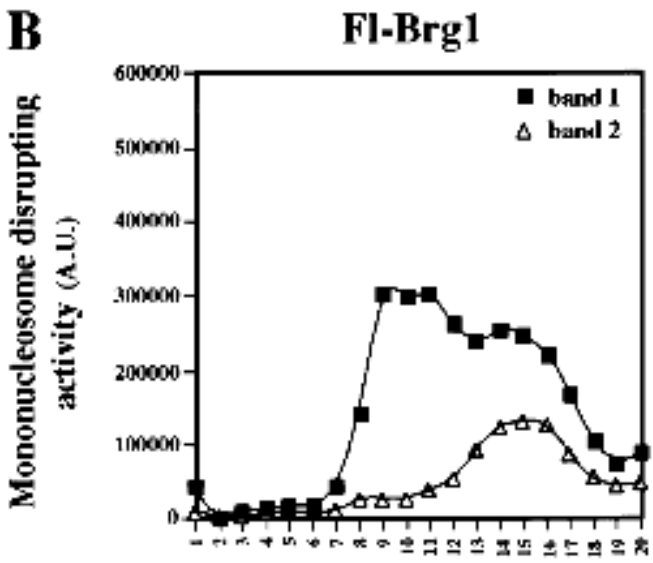

Fraction \#

C

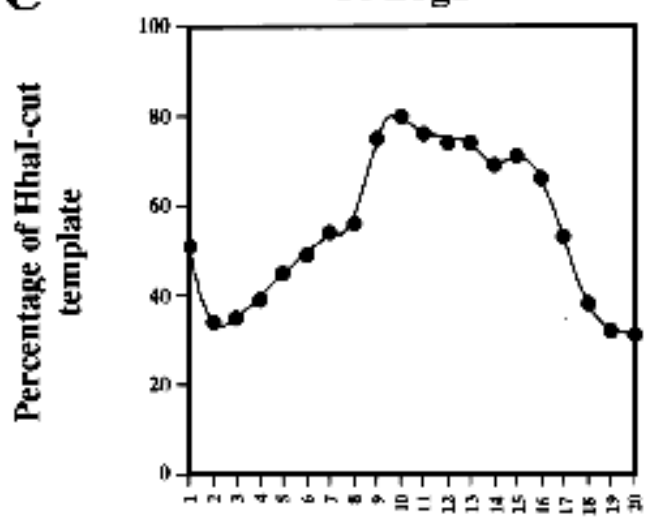

Fraction \#
Fl-Brg1(K798R)

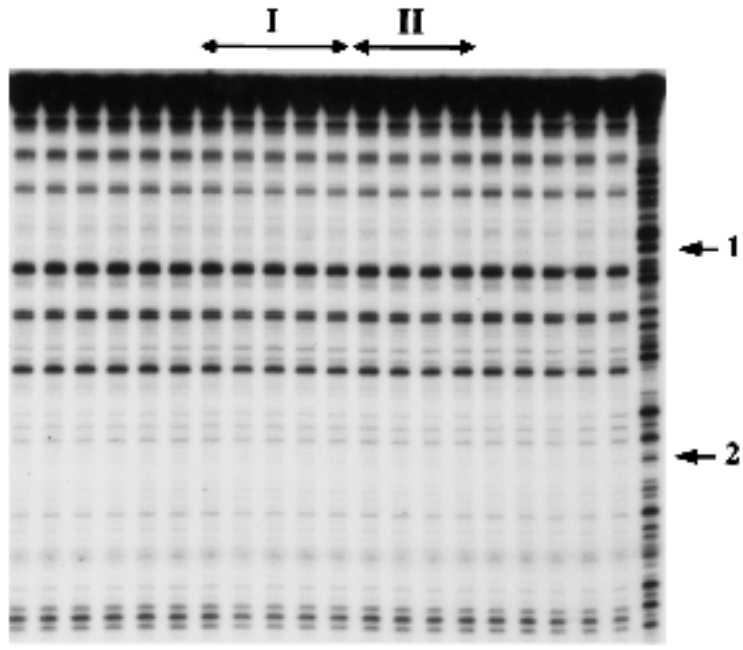

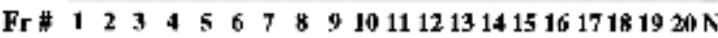

\section{Fl-Brg1(K798R)}

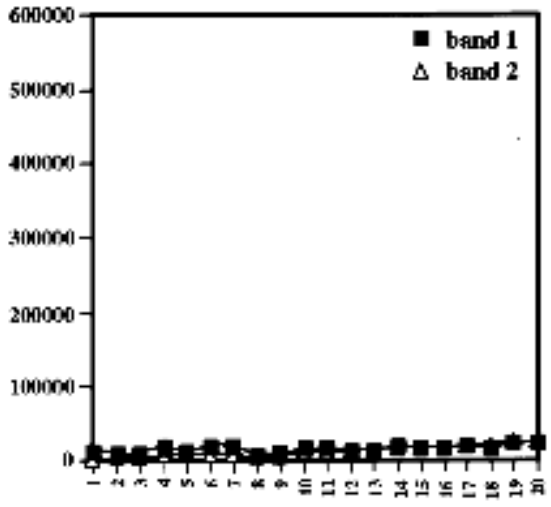

Fraction \#

FI-Brg1 (K798R)

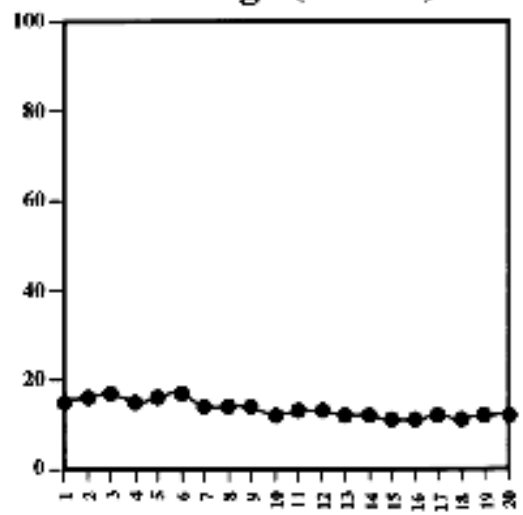

Fraction \#

Figure 7. Characterization of the chromatin remodeling activity of glycerol gradient-purified fractions. $(A)$ Wild-type Fl-Brg1 complexes I and II can remodel nucleosomal core particles. DNase I disruption assays were performed as described in Materials and Methods. Mutant Fl-Brg1 (K798R) complexes were inactive. (Fr.\#) Fraction number; (N) naked DNA; (arrows 1 and 2) bands used to quantify the nucleosome remodeling activity of each fraction in arbitrary units (A.U.). (B) Quantification of bands 1 (filled squares) and 2 (open triangles) revealed that the peaks of nucleosome remodeling activity correlate with the elution profile of active Brgl complexes. (C) Fl-Brg1 complexes can remodel nucleosomal arrays and increase restriction enzyme accessibility. Equal amounts of each fraction $(10 \mu \mathrm{L})$ were incubated with the $5 \mathrm{~S}$ array and assayed for activity by incubating the remodeled template with $H$ haI. The percentage of cut template represents the ratio of cut template to total DNA. 
7A,C, Fl-Brg1/K798R panels), showing that the chromatin remodeling activity of these complexes depends on having an active Brgl ATPase.

Fractionation of the Fl-Inil complexes, which contain a mixture of $\mathrm{Brg} 1$ and $\mathrm{hBrm}$-based complexes, resulted in a broad peak of chromatin remodeling activity (Fig. 8). The activity in the DNase I disruption protocol correlated with the presence of Brgl and hBrm (cf. Fig. 8, FlInil panels, with Fig. 5B), and displayed a disruption pattern that was similar to the disruption observed with Brg1 complexes I and II (cf. Fig. 8A with 7A). Analysis of the Fl-hBrm complexes revealed that there is one peak of activity in the restriction enzyme accessibility protocol (Fig. 8C). These fractions had no activity in the DNase I disruption protocol, as expected (Fig. 8A,B). These results indicate that the hBrm complex has less activity than each of the two Brgl-based complexes.

\section{Discussion}

The Brg1 and hBrm complexes that we have characterized display significant functional differences. The two Brgl complexes can efficiently remodel nucleosomes as core particles as well as arrays, whereas the hBrm complex can remodel only arrays of nucleosomes. These complexes also differ in composition. One of the Brgl complexes and the hBrm complex associate with $\mathrm{mSin} 3 \mathrm{~A}$, a repressor that is involved in the mechanisms that regulate cell growth. It had been recognized previously that there are multiple members of the SWI/SNF family of remodeling complexes. One possibility is that these differences cause these complexes to be targeted differentially to different genes. The studies reported here show that these complexes will bring different remodeling capabilities when they are targeted to genes and also that they can bring, by association, proteins involved directly in repression. The hSWI/SNF family of complexes is therefore likely to contribute more broadly to regulation of gene expression than previously thought.

\section{Brg1 and hBrm complexes are functionally different}

Studies that examined the levels of Brg1 and hBrm under either growth-inhibiting or growth-inducing conditions indicated that the levels of $\mathrm{hBrm}$ increase in cells that have withdrawn from the cell cycle and decrease in cells that are actively dividing (Muchardt et al. 1998). Based on these results, it was proposed that $\mathrm{hBrm}$ negatively regulates cell growth (Muchardt et al. 1998; Reyes et al. 1998). Other evidence that supports the notion that Brg1 and $\mathrm{hBrm}$ are different stems from the findings that show that Brg1 and hBrm complexes are inactivated by phosphorylation in vivo; however, only the hBrm complex is targeted for degradation during mitosis (Muchardt et al. 1996; Sif et al. 1998).

We have now purified complexes that contain either $\mathrm{Brg} 1$ or hBrm from HeLa cells and showed that Brgl is associated with at least two different complexes, which differ by their subunit composition, lack HDAC1, and contain low levels of HDAC2. In contrast, hBrm is found in one complex that contains both HDAC1 and HDAC2. We have also shown that $\mathrm{mSin} 3 \mathrm{~A}$ cofractionates with Brg1 complex I and the hBrm complex and can interact with Brg1, hBrm, and BAF155 in vitro. The differential ability of Brgl and hBrm complexes to associate with different members of the Sin 3 complex might be a key reason for the differences that these complexes play in biological regulation.

Using different assays, we have shown that the Brg1 complexes are more active than the hBrm complex, particularly in their ability to remodel mononucleosome templates. There are several possible explanations for why the hBrm complex does not remodel chromatin as efficiently as the Brgl complexes. The possibility that we favor is that additional subunits repress the remodeling activity of the hBrm complex. Add-back experiments show that when immunopurified Fl-hBrm complex is added in stoichiometric amounts to Fl-Brgl complexes, it can decrease the remodeling activity on nucleosomal arrays (data not shown). In contrast, experiments using baculovirus-expressed proteins show that Fl-Brgl and Fl-hBrm have similar specific activities (G.J. Narlikar and R.E. Kingston, unpubl.), and addition of affinity-purified Fl-hBrm to Fl-Brgl does not inhibit the ability of Brgl to remodel nucleosomal arrays (Phelan et al. 1999). Thus, inhibition in these add-back experiments requires proteins other than the ATPase. One attractive possibility is that HDAC1 and HDAC2 directly affect the remodeling activity of the hBrm complex; these proteins are found associated predominantly with hBrm (Figs. 1C and 5D).

\section{Brg1 is the ATPase of two distinct chromatin remodeling complexes}

Purification of affinity-purified mutant and wild-type FlBrg1 complexes by glycerol gradient sedimentation revealed that there exist two different complexes that contain Brg1 as their central ATPase. Fl-Brg1 complex I contains all known hSWI/SNF subunits; however, Fl-Brg1 complex II lacks p50, and p60 and p220 doublets. It remains possible that $\mathrm{Fl}-\mathrm{Brg} 1$ complex II is a partial version of complex I, but we believe that this is very unlikely because the missing subunits are not limiting (data not shown). Both complexes can remodel nucleosomal arrays and display different mononucleosomal disrupting activities. Complexes that were isolated through Fl-Brg1 (K798R) were inactive in all assays, indicating that Brgl is the major ATPase in these complexes. Furthermore, we have noticed that the levels of mSin3A and RbAp48 are reduced in mutant $\mathrm{Brg} 1$ affinity-purified fractions. It is possible that these two genes might require $\mathrm{Brg} 1 \mathrm{com}-$ plexes for their expression. Therefore, when mutant Brg1, which is unable to remodel chromatin, is expressed, it partially interferes with their activation.

There are clear differences in the way Brgl complexes I and II alter nucleosome structure, as shown by the mononucleosome disruption assay (Fig. 7A,B). Brg1 complex I disrupts the edge of the nucleosome and shows 
Sif et al.

$\mathbf{A}$
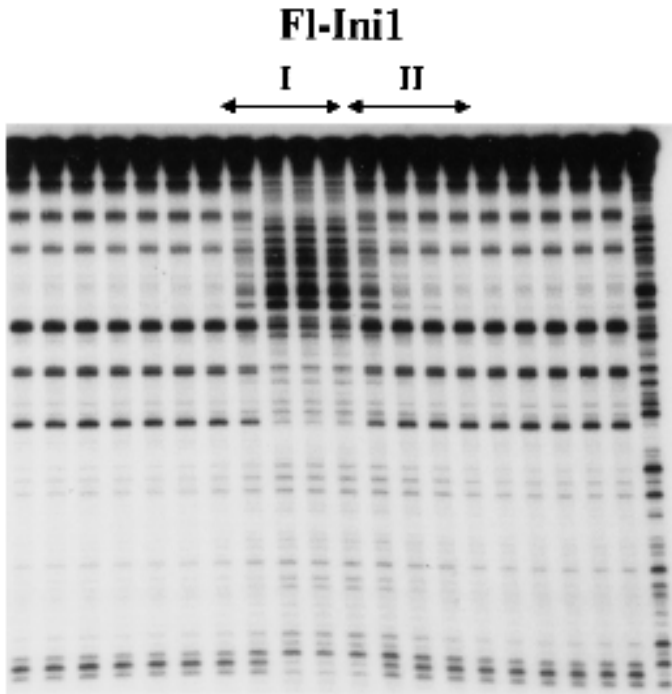

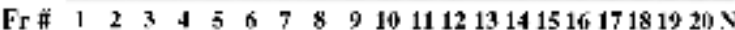

B

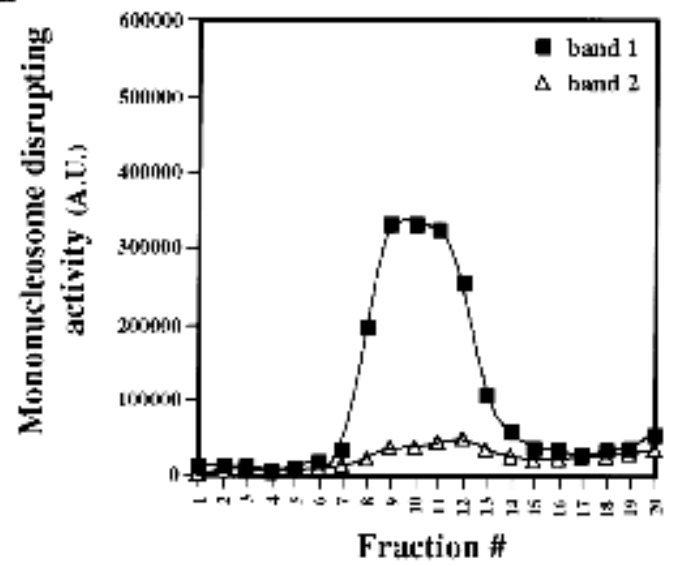

C

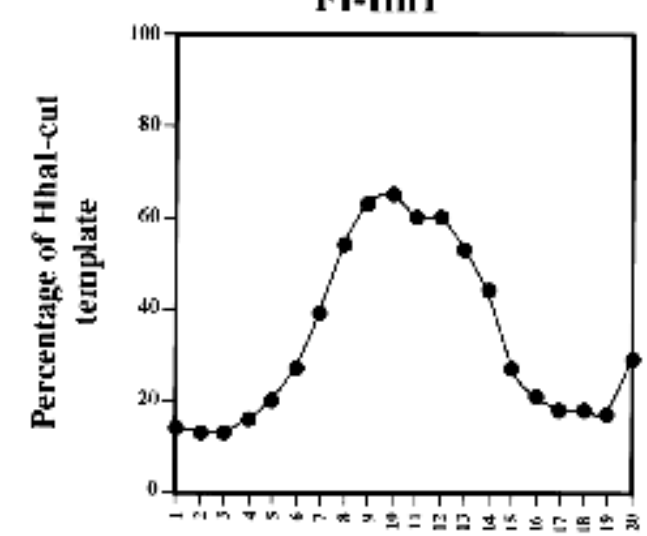

Fraction \#
FL-hBrm
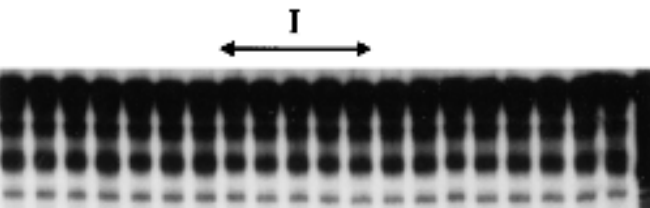

$\leftarrow 1$

-

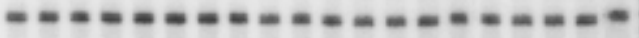

$------\cdots-\cdots-\cdots$

$-2$

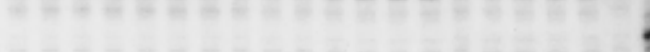

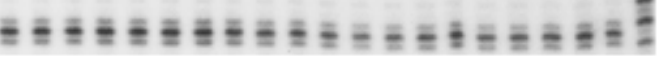

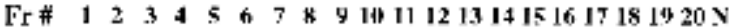

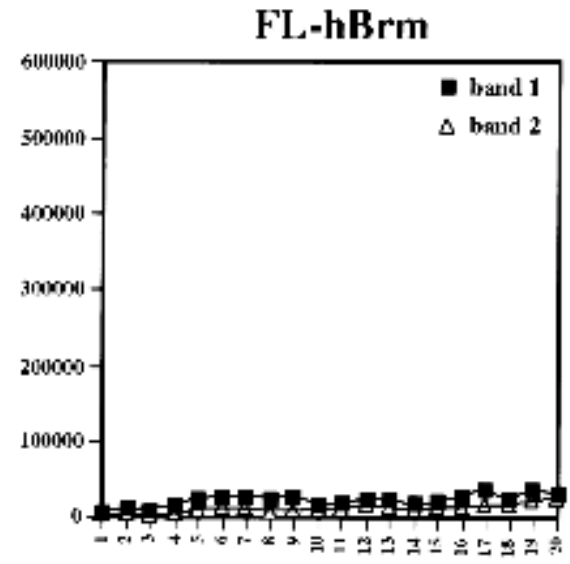

Fraction \#

FL-hBrm

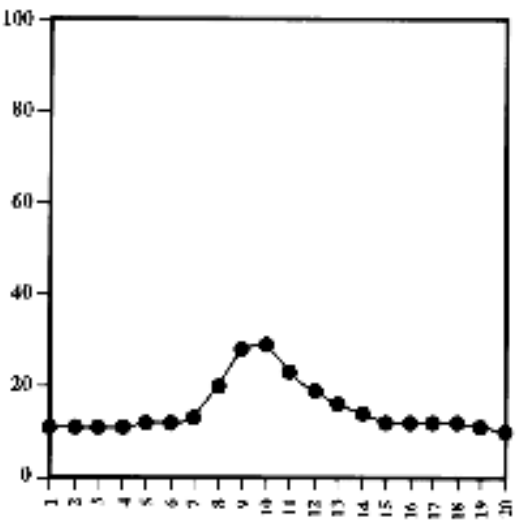

Fraction \#

Figure 8. Chromatin remodeling activity of Fl-Inil and Fl-hBrm complexes. (A) Fl-Inil and Fl-hBrm glycerol gradient fractions $(10 \mu \mathrm{L}$ each) were incubated with nucleosome cores as described in Materials and Methods. Fl-Inil fractions show a single broad peak of nucleosome-disrupting activity, which correlates with the activity of anti-Brgl and anti-hBrm antibodies. Fl-hBrm complex did not alter the mononucleosome 10-bp ladder. (Fr.\#) Fraction number; (N) naked DNA; (arrows 1 and 2) bands used to generate the graphs shown in $B .(C)$ Fl-Inil and Fl-hBrm complexes can remodel nucleosomal arrays. Equal amounts $(10 \mu \mathrm{L})$ of each glycerol gradient fraction were assayed for activity as described for Fl-Brgl complexes. The percentage of cut template represents the ratio of cut template to total DNA. 
protection from DNase I cleavage near the dyad axis. In contrast, Brgl complex II induces cutting throughout the nucleosome cores. It is likely that the lack of certain subunits in Brg1 complex II might contribute to the widespread disruption of the nucleosome ladder. Evidence that supports this hypothesis comes from studies by Wang et al. (1998), which show that BAF57 (p50 in our complexes) can avidly bind four-way junction DNA through its HMG-like DNA binding domain. Based on this result and the studies of Quinn et al. (1996), it was speculated that BAF57 might bind nucleosomes near the dyad axis, where DNA enters and exits the nucleosome, and therefore might adopt a structure that resembles a four-way junction. Our results show that Brgl complex I, which contains p50 (BAF57), can induce protection over the region that spans the dyad axis. In contrast, Brg1 complex II, which lacks p50 as well as p60 and p220 subunits, shows a different pattern of disruption of the 10-bp ladder. Therefore, it is possible that the p50 subunit either alone or in combination with other hSWI/ SNF subunits is responsible for blocking remodeling at the dyad axis.

There is ample evidence indicating that chromatin remodeling complexes are targeted by transcription factors to perform specific changes at specific loci (Cosma et al. 1999; Gregory et al. 1999; Krebs et al. 1999). The nature of the changes introduced by chromatin remodeling complexes is still not clear, although it is likely that these changes are going to be regulated and specific in nature. Recent studies have shown that the yeast SWI/ SNF and RSC complexes can remodel nucleosomes by catalyzing the transfer of the core histones in cis or in trans (Lorch et al. 1999; Whitehouse et al. 1999; Jaskelioff et al. 2000). In contrast, members of the ISWI subfamily of chromatin remodeling complexes can alter nucleosome structure by promoting histone octamer sliding in cis, but not in trans (Hamiche et al. 1999; Längst et al. 1999). Therefore, different classes of transcription factors might exploit the intrinsic differences that exist between different forms of remodeling complexes to induce specific alterations of nucleosome structure. For example, Brg1 complex I might be recruited to induce changes in localized regions of the nucleosome, whereas Brgl complex II might be targeted to cause a more widespread disruption of chromatin. It is also conceivable that the difference in activity between Brg1 and hBrm complexes might be used selectively by various transcription factors to achieve different levels of chromatin remodeling.

\section{Interaction of Brg1 and hBrm complexes with components of the Sin3 complex}

Several studies have shown that multisubunit chromatin remodeling complexes can act in concert with histone acetyl transferases to activate transcription /Cosma et al. 1999; Gregory et al. 1999; Krebs et al. 1999|. More recently, members of the Mi-2 subfamily of ATPases have been found in association with HDAC1 and 2, providing a link between chromatin remodeling and histone deacetylation (Tong et al. 1998; Xue et al. 1998; Zhang et al. 1998a). We now show that Brgl and hBrm complexes associate with components of the Sin 3 complex, which has been shown to be involved in the repression of transcription by a wide variety of factors. Characterization of the chromatin remodeling activity of these complexes shows that they have different specific activities and can alter nucleosome structure in a different manner. Taken together, these results indicate that proteins that target the $\operatorname{Sin} 3 \mathrm{~A} /$ histone deacetylase complex might also indirectly target the Brgl and hBrm complexes. Precedents for such a mechanism are provided by the NuRD complex, which has been shown to be targeted by factors that can repress transcription (Kim et al. 1999; O'Neill et al. 2000).

There are several questions that remain unanswered. For example, why is HDAC1 not present in the Brg1 complexes? Why is $\mathrm{mSin} 3 \mathrm{~A}$ found in association only with Brgl complex I and not with complex II? Both complexes remodel nucleosomes; however, it appears that Brg1 complex I has a different pattern of disruption of the 10-bp ladder than complex II. Does this mean that the Sin 3 complex can interact only with complexes that can induce localized changes in nucleosome structure? Using the Brgl and hBrm epitope-tagged cell lines, we can begin to address these questions and elucidate the mechanisms by which Brgl and hBrm complexes are regulated and targeted.

\section{Materials and methods}

Plasmid constructions

Plasmid pBabe/Fl-Inil for in vivo expression of C-terminally Flag-tagged Inil was described previously (Sif et al. 1998). Plasmid pBS(KS+)/Fl-Inil was generated by subcloning a $1.2-\mathrm{kb}$ EcoRI fragment excised out of pBabe/Fl-Inil into the unique EcoRI site of Bluescript. Retroviral vectors used to express Cterminally Flag-tagged wild-type and mutant Brgl, and hBrm, were generated using inserts from $\mathrm{pBS}(\mathrm{KS}+) / \mathrm{Fl}-\mathrm{Brg} 1, \mathrm{pBS}(\mathrm{KS}+) /$ Fl-Brg1 (K798R), and pBS(KS+)/Fl-hBrm, respectively. To generate $\mathrm{pBS}(\mathrm{KS}+) / \mathrm{Fl}-\mathrm{Brg} 1$, full-length $\mathrm{Brg} 1$ was excised out of $\mathrm{pBJ5/}$ Brg1 (Khavari et al. 1993) as an HpaI fragment and subcloned into EcoRV-linearized pBS(KS+). Two primers were then used to introduce a Flag tag before the stop codon followed by SaII and SpeI restriction sites. The $5^{\prime}$ primer $\left(5^{\prime}\right.$-GAC CAA GAC CCT GAT GAA CAC CAT CAT GCA GCT GCG GAA GAT CTG CAA CCA CCC CTA CAT GTT CCA GCAC-3') spanned the BgIII site at nucleotide position 3190 , and the $3^{\prime}$ primer $\left(5^{\prime}\right.$-GAC TAG TCG CGT CGA CTT ATC ATT TGT CAT CGT C $\overline{\mathbf{G T}}$

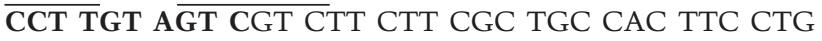
AGC GGT CCT CCT CT-3') contained the Flag-tag, SalI, and SpeI sequences. Flag sequences are indicated in boldface, and the restriction sites are underlined. The PCR fragment generated with these primers was then subcloned into $\mathrm{pBS}(\mathrm{KS}+) / \mathrm{Brg} 1$, which was digested with BglII-SpeI, thereby generating pBS(KS+)/Fl-Brg1. The full-length Flag-tagged Brg1 cDNA was then excised out of $\mathrm{pBS}(\mathrm{KS}+) / \mathrm{Fl}-\mathrm{Brg} 1$ as a SalI fragment and subcloned into pBabe to generate pBabe/Fl-Brg1. To create Flagtagged Brgl containing a mutation in the ATP binding site, which substitutes a lysine at amino acid position 798 for an arginine, an NsiI-BglII restriction fragment was isolated from pBJ5/Brg1 (K798R) (Khavari et al. 1993) and subcloned into the 
respective sites of $\mathrm{pBS}(\mathrm{KS}+) / \mathrm{Fl}-\mathrm{Brg} 1$. Plasmid pBabe/Fl-Brg1 (K798R) was generated by subcloning a SalI fragment from pBS(KS+)/Fl-Brg1 (K798R) into SalI-linearized pBabe. Plasmids pBS(KS+)/BAF155 and pBS(KS-)/BAF60 were described previously (Wang et al. 1996b; Phelan et al. 1999). Plasmid pBS(KS+)/ Fl-hBrm was constructed as follows. First, two primers were designed so that the $5^{\prime}$ primer $\left(5^{\prime}\right.$-CGC AGC AAC AAC AGC AGC CGG CCC TTG TTA ACT ACA ACA GAC CAT CTG GCC CGG GGC CGG AGC TGA GCG G-3') spanned the internal HpaI site at nucleotide position 1070, and the $3^{\prime}$ primer (5'-CGG GGT ACC CGG AAT TCT TAT CAT TTG TCA TCG TCG TCC TTG TAG TCC TCA TCA TCC GTC CCA CTT CCT TCT GAC TGT TCA CGT-3') encoded the Flag tag followed by EcoRI and KpnI restriction sites. These two primers were used to generate a PCR fragment from pCG/hBrm (Muchardt and Yaniv 1993), which was digested with $H p a I$ and KpnI and cloned back into pCG/hBrm. The resulting plasmid, pCG/FlhBrm, was digested subsequently with EcoRI, and the fulllength Flag-tagged hBrm cDNA was cloned as an EcoRI fragment into pBabe. Plasmids pTPT and p2085S-G5E4 used to generate the DNA fragments to assemble mononucleosomal core particles and the 5S nucleosomal arrays, respectively, were described previously (Sif et al. 1998; Neely et al. 1999).

\section{Establishment of cell lines}

Cells were grown in Dulbecco's modified Eagle's media (DMEM) supplemented with $10 \%$ fetal bovine serum (FBS). To create cell lines that express Flag-tagged wild-type and mutant Brgl, and hBrm, retroviral vectors for the expression of these proteins were transfected into the Bing packaging cell line essentially as described (Sif et al. 1998). Several individual colonies were isolated for each construct, expanded into cell lines, and screened for expression. Two clones for each construct were expanded into media containing puromycin and used to immunopurify Brgl and hBrm complexes.

\section{Purification of Flag-tagged hSWI/SNF complexes}

Nuclear extracts were prepared from each cell line as described previously (Dignam et al. 1983). Affinity purification of epitopetagged hSWI/SNF complexes was performed as described previously (Sif et al. 1998). To further purify hSWI/SNF complexes, approximately $4 \mu \mathrm{g}$ of affinity-purified complexes was applied to a $2-\mathrm{mL} 20 \%-40 \%$ glycerol gradient (glycerol, $50 \mathrm{mM}$ Tris- $\mathrm{HCl}$ at $\mathrm{pH} 7.5,1 \mathrm{mM}$ EDTA) and centrifuged in a TLS55 rotor at $30,000 \mathrm{rpm}$ for $24 \mathrm{~h}$ at $4^{\circ} \mathrm{C}$. Fractions $(\sim 120 \mu \mathrm{L})$ were collected and analyzed as described in the figure legends.

\section{Mononucleosome disruption and ATPase assays}

Mononucleosome disruption assays were performed as described previously (Imbalzano et al. 1996; Sif et al. 1998), except that the core particles were assembled by octamer transfer instead of by salt dilution (Rhodes and Laskey 1989). A 155-bp EcoRI-MluI DNA fragment derived from the pTPT plasmid was ${ }^{32} \mathrm{P}$-labeled at the EcoRI site by Klenow treatment and assembled into core particles in the presence of 80 -fold molar excess of H1-depleted HeLa nucleosomes. Assembled cores were applied to a $5 \%-30 \%$ glycerol gradient and purified as described (Sif et al. 1998). Approximately $3.3 \mathrm{ng}(0.44 \mathrm{nM})$ of nucleosomal core particles, which includes $0.3 \mathrm{ng}(0.04 \mathrm{nM})$ labeled and $3 \mathrm{ng}(0.4 \mathrm{nM})$ unlabeled DNA, were incubated with or without $2 \mathrm{mM}$ ATP and affinity-purified Brg1 and hBrm complexes in a $25-\mu \mathrm{L}$ reaction containing $12 \mathrm{mM}$ HEPES ( $\mathrm{pH} 7.9$ ), 60 $\mathrm{mM} \mathrm{KCl}, 6 \mathrm{mM} \mathrm{MgCl}_{2}, 60 \mu \mathrm{M}$ EDTA, 2 mM DTT, $13 \%$ glyc- erol for $30 \mathrm{~min}$ at $30^{\circ} \mathrm{C}$. DNase I treatment and analysis were as described (Sif et al. 1998). To measure the ATPase activity of Brg1 and hBrm complexes, approximately $72 \mathrm{ng}(3.6 \mathrm{nM})$ of immunopurified complexes was incubated with or without 20 $\mathrm{nM}$ plasmid DNA and $100 \mu \mathrm{M}$ ATP in a $10-\mu \mathrm{L}$ reaction as described (Phelan et al. 1999).

\section{Chromatin remodeling assays}

Nucleosome-assembled plasmid templates used in the supercoiling assay were prepared as described previously (Sif et al. 1998). Nucleosome reconstitution of Lytechinus variegatus $5 S$ ribosomal DNA repeat sequences was performed using plasmid p2085S-G5E4 (Neely et al. 1999). The 5S array was gel purified following digestion of p2085S-G5E4 with Asp718, ClaI, and DdeI, ${ }^{32}$ P-labeled at the Asp 718 site by Klenow treatment, and used to assemble polynucleosomal templates as reported previously (Richmond et al. 1988; Carruthers et al. 1999). Briefly, a total of $10 \mu \mathrm{g}$ of gel-purified 5S-G5E4 fragment was incubated with $13.1 \mu \mathrm{g}$ of H1-depleted HeLa core histones in a 100- $\mu \mathrm{L}$ final reaction volume containing high salt buffer $(2 \mathrm{M} \mathrm{NaCl}, 20 \mathrm{mM}$ Tris- $\mathrm{HCl}$ at $\mathrm{pH}$ 7.8, $1 \mathrm{mM}$ EDTA, $10 \mathrm{mM}$ DTT, $0.5 \mathrm{mM}$ benzamidine hydrochloride) supplemented with $100 \mu \mathrm{g} / \mathrm{mL}$ BSA. The reaction was transferred to a dialysis tubing and placed into 200 $\mathrm{mL}$ of high salt buffer $(2 \mathrm{M} \mathrm{NaCl}, 20 \mathrm{mM}$ Tris- $\mathrm{HCl}$ at $\mathrm{pH} 7.8,1$ mM EDTA, 10 mM DTT, $0.5 \mathrm{mM}$ benzamidine hydrochloride). Assembly of the $5 \mathrm{~S}$ array was performed by continuous dilution of the dialysis buffer using a low salt buffer $(0.25 \mathrm{M} \mathrm{NaCl}, 20$ $\mathrm{mM}$ Tris- $\mathrm{HCl}$ at $\mathrm{pH}$ 7.8, $1 \mathrm{mM}$ EDTA, $10 \mathrm{mM}$ DTT, $0.5 \mathrm{mM}$ benzamidine hydrochloride) and keeping the volume of the dialysis reaction constant. Dialysis was allowed to proceed for 48 $\mathrm{h}$ until the salt concentration of the dialysis buffer was lower than $500 \mathrm{mM} \mathrm{NaCl}$. The assembled $5 \mathrm{~S}$ linear array was stabilized by a final dialysis in $200 \mathrm{~mL}$ of a buffer containing $10 \mathrm{mM}$ Tris- $\mathrm{HCl}(\mathrm{pH} 7.8)$ and $0.25 \mathrm{mM}$ EDTA for $12-16 \mathrm{~h}$ at $4^{\circ} \mathrm{C}$ (Hansen et al. 1991). The amount of HeLa core histones added to the initial reaction was determined empirically as one that resulted in more than $50 \%$ saturated arrays as determined by EcoRI digestion analysis (Carruthers et al. 1999), concomitant increases in agarose gel electrophoretic mobility (Steger and Workman 1999), and micrococcal nuclease (MNase) digestion.

To analyze the extent of assembly of the 5S array, we treated $2 \mathrm{ng}$ of unlabeled and assembled template with increasing amounts of MNase for $2 \mathrm{~min}$ at room temperature. The reactions were stopped with stop buffer $(50 \mathrm{mM}$ Tris- $\mathrm{HCl}$ at $\mathrm{pH} 8.0$, $0.1 \mathrm{mM}$ EDTA, 25\% (v/v) glycerol, 3\% (w/v) SDS, 0.04\% (w/v) bromophenol blue, $0.04 \%(\mathrm{w} / \mathrm{v})$ xylene cyanol), which was supplemented with $2 \mathrm{mg} / \mathrm{mL}$ proteinase $\mathrm{K}$, and incubated for $45-60 \mathrm{~min}$ at $37^{\circ} \mathrm{C}$. Samples were loaded on a $1 \%$ agarose gel and electrophoresed for $12-15 \mathrm{~h}$ at $60 \mathrm{~V}$. The denatured DNA was transferred to Hybond-XL membrane (Amersham Pharmacia Biotech) overnight in $20 \times \mathrm{SSC}$ ( $3 \mathrm{M} \mathrm{NaCl}, 0.3 \mathrm{M}$ sodium citrate at $\mathrm{pH}$ 7.0). Following UV irradiation to cross-link the DNA, the membrane was prehybridized and hybridized using ExpressHyb hybridization solution (Clontech) according to the manufacturer's protocol. A 5S-specific oligonucleotide (5'-GGT ATG GTC GTA GGC TCT TGC TTG-3') was ${ }^{32}$ P-labeled by kinase treatment and used at $2 \times 10^{6} \mathrm{cpm} / \mathrm{mL}$ of hybridization solution to detect the 5S DNA.

To assay for nucleosome remodeling, $6 \mathrm{ng}$ of either plasmid chromatin $(0.12 \mathrm{nM})$ or $5 \mathrm{~S}$ nucleosomal arrays $(0.14 \mathrm{nM})$ was incubated with or without ATP and Brgl and hBrm complexes in a $25-\mu \mathrm{L}$ reaction as described for the mononucleosome disruption assay. Reactions that contained plasmid chromatin were supplemented with 0.1 unit of wheat germ topoisomerase I (Promega) and incubated for $60-90 \mathrm{~min}$ at $30^{\circ} \mathrm{C}$. When the $5 \mathrm{~S}$ 
nucleosomal array was added, samples were incubated with remodeling complexes for either 10 or $30 \mathrm{~min}$ at $30^{\circ} \mathrm{C}$ before adding apyrase (2.5 units per reaction). Next, HhaI was added (15 units per reaction), and the reactions were allowed to incubate for an additional $60 \mathrm{~min}$ at $30^{\circ} \mathrm{C}$. All reactions were stopped with stop buffer containing $2 \mathrm{mg} / \mathrm{mL}$ proteinase $\mathrm{K}$ and were incubated for $45-60 \mathrm{~min}$ at $37^{\circ} \mathrm{C}$. The samples that contained plasmid DNA were analyzed on a $2 \%$ agarose gel in $1 \times$ phosphate buffer $(40 \mathrm{mM}$ Tris-base, $30 \mathrm{mM} \mathrm{NaPO}$, $1 \mathrm{mM}$ EDTA) for $42 \mathrm{~h}$ at $40 \mathrm{~V}$, whereas samples that contained $5 \mathrm{~S}$ arrays were analyzed on $1 \%$ agarose gel in $1 \times$ TAE buffer $(40$ mM Tris-acetate, $1 \mathrm{mM}$ EDTA) for $4-5 \mathrm{~h}$ at $140 \mathrm{~V}$.

\section{Antibodies and Western blot analysis}

Western blot analysis and anti-Brg1, anti-hBrm, and anti-hSWI3 rabbit polyclonal antisera have been described previously (Sif et al. 1998). Anti-BAF60 rabbit polyclonal antibodies were raised against a GST-BAF60 (amino acids 10-84). Anti-mSin3A and anti-Flag M2 antibodies were purchased from Santa Cruz, antiHDACl and 3 were purchased from Upstate Biotechnologies, and anti-HDAC2 and anti-RbAp48 antibodies were purchased from Zymed.

\section{Immunoprecipitation of in vitro translated proteins}

Proteins were synthesized by incubating 1-2 $\mu \mathrm{g}$ of plasmid DNA with $25 \mu \mathrm{L}$ of the TNT-coupled reticulocyte lysate and 22 $\mu \mathrm{Ci}$ of $\left[{ }^{35} \mathrm{~S}\right]$ methionine and cysteine (NEN) according to the manufacturers recommendations (Promega). In vitro translated proteins were immunoprecipitated by incubating $40-50 \times 10^{3}$ cpm with antibodies in a $250-\mu \mathrm{L}$ reaction containing $20 \mathrm{mM}$ Tris- $\mathrm{HCl}$ (pH 7.4), $100 \mathrm{mM} \mathrm{NaCl}, 5 \mathrm{mM} \mathrm{MgCl} 2,1 \mathrm{mM}$ EDTA, $0.1 \%$ NP-40, $1 \%$ Aprotinin. After a 60 min incubation on ice, 75 $\mu \mathrm{L}$ of a $50 \%$ slurry of protein A sepharose beads (Pharmacia) was added, and the reactions were incubated overnight at $4^{\circ} \mathrm{C}$ with gentle mixing. When anti-Flag M2 affinity gel was used, protein A sepharose beads were not added. After the first immunoprecipitation, beads were washed three times with $0.5 \mathrm{~mL}$ of washing buffer $(20 \mathrm{mM}$ Tris- $\mathrm{HCl}$ at $\mathrm{pH} 7.4,150 \mathrm{mM} \mathrm{NaCl}, 5 \mathrm{mM}$ $\mathrm{MgCl}_{2}, 1 \mathrm{mM}$ EDTA, $0.1 \%$ NP-40, 1\% Aprotinin). The retained proteins were then released by heat denaturation for $5 \mathrm{~min}$ in the presence of $0.5 \%$ SDS, and the supernatant was used to perform a second immunoprecipitation using specific antibodies as described above. Beads were washed four times with washing buffer and analyzed by SDS-PAGE.

\section{Acknowledgments}

We thank R.N. Eisenman, J. Workman, and K. Neely for providing plasmids; W. Wang, A. Kuzmicher, and D. Reinberg for providing antibodies; H. Su for help generating cell lines; and J. Vandeusen and M. Caligiuri for help with the PhosphorImager. We thank C. Varughese and M. Hirschel from Cellex Biosciences, Inc., for growing cell lines. We are grateful to K. Lee, T. Gilmore, S. Ackerman, and C. Peterson for critical reading of the manuscript. A.J.S. is a Human Frontier Science Program fellow. This work is supported by NIH grant GM48405 to R.E.K and by the James Cancer Hospital and Solove Research Institute Research Fund and NCI grant 1 K01 CA89854-01 to S.S.

The publication costs of this article were defrayed in part by payment of page charges. This article must therefore be hereby marked "advertisement" in accordance with 18 USC section 1734 solely to indicate this fact.

\section{References}

Alland, L., Muhle, R., Hou Jr., H., Potes, J., Chin, L., SchreiberAgus, N., and DePinho, R.A. 1997. Role for N-CoR and histone deacetylase in Sin3-mediated transcriptional repression. Nature 387: 49-55.

Bird, A.P. and Wolffe, A.P. 1999. Methylation-induced repression-belts, braces, and chromatin. Cell 99: 451-454.

Carruthers, L.M., Tse, C., Walker, K.P., and Hansen, J.C. 1999. Assembly of defined nucleosomal and chromatin arrays from pure components. Methods Enzymol. 304: 19-35.

Chiba, H., Muramatsu, M., Nomoto, A., and Kato, H. 1994. Two human homologues of Saccharomyces cerevisiae SWI2/ SNF2 and Drosophila brahma are transcriptional coactivators cooperating with the estrogen receptor and the retinoic acid receptor. Nucleic Acids Res. 22: 1815-1820.

Cosma, M.P., Tanaka, T., and Nasmyth, K. 1999. Ordered recruitment of transcription and chromatin remodeling factors to a cell cycle- and developmentally regulated promoter. Cell 97: 299-311.

Dignam, J.D., Martin, P.L., Shastry, B.S., and Roeder, R.G. 1983. Eukaryotic gene transcription with purified components. Methods Enzymol. 101: 582-598.

Dunaief, J.L., Strober, B.E., Guha, S., Khavari, P.A., Alin, K., Luban, J., Begemann, M., Crabtree, G.R., and Goff, S.P. 1994. The retinoblastoma protein and BRG1 form a complex and cooperate to induce cell cycle arrest. Cell 79: 119-130.

Eisen, J.A., Sweder, K.S., and Hanawalt, P.C. 1995. Evolution of the SNF2 family of proteins: Subfamilies with distinct sequences and functions. Nucleic Acids Res. 23: 2715-2723.

Gregory, P.D., Schmid, A., Zavari, M., Münsterkötter, M., and Hörz, W. 1999. Chromatin remodelling at the PHO8 promoter requires SWI-SNF and SAGA at a step subsequent to activator binding. EMBO J. 18: 6407-6414.

Grunstein, M. 1997. Histone acetylation in chromatin structure and transcription. Nature 389: 349-352.

Hamiche, A., Sandaltzopoulos, R., Gdula, D.A., and Wu, C. 1999. ATP-dependent histone octamer sliding mediated by the chromatin remodeling complex NURF. Cell 97: 833-842.

Hansen, J.C., Van Holde, K.E., and Lohr, D. 1991. The mechanism of nucleosome assembly onto oligomers of the sea urchin 5S DNA positioning sequence. J. Biol. Chem. 266: 4276-4282.

Hassig, C.A., Fleischer, T.C., Billin, A.N., Schreiber, S.L., and Ayer, D.E. 1997. Histone deacetylase activity is required for full transcriptional repression by mSin3A. Cell 89: 341-347.

Imbalzano, A.N., Schnitzler, G.R., and Kingston, R.E. 1996. Nucleosome disruption by human SWI/SNF is maintained in the absence of continued ATP hydrolysis. J. Biol. Chem. 271: 20726-20733.

Jaskelioff, M., Gavin, I.M., Peterson, C.L., and Logie, C. 2000. SWI/SNF mediated nucleosome remodeling: Role of histone octamer mobility in the persistence of the remodeled state. Mol. Cell. Biol. 20: 3058-3068.

Khavari, P.A., Peterson, C.L., Tamkun, J.W., and Crabtree, G.R. 1993. BRG1 contains a conserved domain of the SWI2/SNF2 family necessary for normal mitotic growth and transcription. Nature 366: 170-174.

Kim, J., Sif, S., Jones, B., Jackson, A., Koipally, J., Heller, E., Winandy, S., Viel, A., Sawyer, A., Ikeda, T., et al. 1999. Ikaros DNA-binding proteins direct formation of chromatin remodeling complexes in lymphocytes. Immunity 10: 345355.

Kingston, R.E. and Narlikar, G.J. 1999. ATP-dependent remodeling and acetylation as regulators of chromatin fluidity. 
Genes \& Dev. 13: 2339-2352.

Knoepfler, P.S. and Eisenman, R.N. 1999. Sin meets NuRD and other tails of repression. Cell 99: 447-450.

Kouzarides, T. 1999. Histone acetylases and deacetylases in cell proliferation. Curr. Opin. Genet. Dev. 9: 40-48.

Krebs, J.E., Kuo, M.-H., Allis, C.D., and Peterson, C.L. 1999. Cell cycle-regulated histone acetylation required for expression of the yeast HO gene. Genes \& Dev. 13: 14121421.

Kwon, H., Imbalzano, A.N., Khavari, P.A., Kingston, R.E., and Green, M.R. 1994. Nucleosome disruption and enhancement of activator binding by a human SWI/SNF complex. Nature 370: 477-481.

Laherty, C.D., Yang, W.-M., Sun, J.-M., Davie, J.R., Seto, E., and Eisenman, R.N. 1997. Histone deacetylases associated with the mSin3 corepressor mediate Mad transcriptional repression. Cell 89: 349-356.

Längst, G., Bonte, E.J., Corona, D.F.V., and Becker, P.B. 1999. Nucleosome movement by CHRAC and ISWI without disruption or trans-displacement of the histone octamer. Cell 97: 843-852.

Lorch, Y., Zhang, M., and Kornberg, R. D. 1999. Histone octamer transfer by a chromatin-remodeling complex. Cell 96: 389-392.

Muchardt, C. and Yaniv, M. 1993. A human homologue of Saccharomyces cerevisiae SNF2/SWI2 and Drosophila brm genes potentiates transcriptional activation by the glucocorticoid receptor. EMBO J. 12: 4279-4290.

Muchardt, C., Reyes, J.-C., Bourachot, B., Leguoy, E., and Yaniv, M. 1996. The hbrm and BRG-1 proteins, components of the human SNF/SWI complex, are phosphorylated and excluded from the condensed chromosomes during mitosis. EMBO $J$. 15: 3394-3402.

Muchardt, C., Bourachot, B., Reyes, J.-C., and Yaniv, M. 1998. ras transformation is associated with decreased expression of the brm/SNF2 $\alpha$ ATPase from the mammalian SWI-SNF complex. EMBO J. 17: 223-231.

Murphy, D.J., Hardy, S., and Engel, D.A. 1999. Human SWI-SNF component BRG1 represses transcription of the c-fos gene. Mol. Cell. Biol. 19: 2724-2733.

Nagy, L., Kao, H.-Y., Chakravarti, D., Lin, R.J., Hassig, C.A., Ayer, D.E., Schreiber, S.L., and Evans, R.M. 1997. Nuclear receptor repression mediated by a complex containing SMRT, mSin3A, and histone deacetylase. Cell 89: 373-380.

Neely, K.E., Hassan, A.H., Wallberg, A.E., Steger, D.J., Cairns, B.R., Wright, A.P., and Workman, J.L. 1999. Activation domain-mediated targeting of the SWI/SNF complex to promoters stimulates transcription from nucleosome arrays. Mol. Cell 4: 649-655.

O'Neill, D.W., Schoetz, S.S., Lopez, R.A., Castle, M., Rabinowitz, L., Shor, E., Krawchuk, D., Goll, M.G., Renz, M., Seelig, H.-P., et al. 2000. An Ikaros-containing chromatin remodeling complex in adult-type erythroid cells. Mol. Cell. Biol. 20: 7572-7582.

Phelan, M.L., Sif, S., Narlikar, G.J., and Kingston, R.E. 1999. Reconstitution of a core chromatin remodeling complex from SWI/SNF subunits. Mol. Cell 3: 247-253.

Quinn, J., Fyrberg, A.M., Ganster, R.W., Schmidt, M.C., and Peterson, C.L. 1996. DNA binding properties of the yeast SWI/SNF complex. Nature 379: 844-847.

Reyes, J.-C., Barra, J., Muchardt, C., Camus, A., Babinet, C., and Yaniv, M. 1998. Altered control of cellular proliferation in the absence of mammalian brahma (SNF2 $\alpha$ ). EMBO $J$. 17: 6979-6991.

Rhodes, D. and Laskey, R.A. 1989. Assembly of nucleosomes and chromatin in vitro. Methods Enzymol. 170: 575-585.
Richmond, T.J., Searles, M.A., and Simpson, R.T. 1988. Crystals of a nucleosome core particle containing defined sequence DNA. J. Mol. Biol. 199: 161-170.

Sif, S., Stukenberg, P.T., Kirschner, M.W., and Kingston, R.E. 1998. Mitotic inactivation of a human SWI/SNF chromatin remodeling complex. Genes \& Dev. 12: 2842-2851.

Singh, P., Coe, J., and Hong, W. 1995. A role for retinoblastoma protein in potentiating transcriptional activation by the glucocorticoid receptor. Nature 374: 562-565.

Steger, D.J. and Workman, J.L. 1999. Transcriptional analysis of purified histone acetyltransferase complexes. Methods: A companion to methods in enzymology 19: 410-416.

Strober, B.E., Dunaief, J.L., Guha, S., and Goff, S.P. 1996. Functional interactions between the hBRM/hBRG1 transcriptional activators and the pRB family of proteins. Mol. Cell. Biol. 16: 1576-1583.

Tong, J.K., Hassig, C.A., Schnitzler, G.R., Kingston, R.E., and Schreiber, S.L. 1998. Chromatin deacetylation by an ATPdependent nucleosome remodelling complex. Nature 395: 917-921.

Vignali, M., Hassan, A.H., Neely, K.E., and Workman, J.L. 2000. ATP-dependent chromatin remodeling complexes. Mol. Cell. Biol. 20: 1899-1910.

Wade, P.A., Jones, P.L., Vermaak, D., and Wolffe, A.P. 1998. A multiple subunit Mi-2 histone deacetylase from Xenopus laevis cofractionates with an associated Snf2 superfamily ATPase. Curr. Biol. 8: 843-846.

Wang, W., Côté, C., Xue, Y., Zhou, S., Khavari, P.A., Biggar, S.R., Muchardt, C., Kalpana, G.V., Goff, S.P., Yaniv, M., et al. 1996a. Purification and biochemical heterogeneity of the mammalian SWI-SNF complex. EMBO J. 15: 5370-5382.

Wang, W., Xue, Y., Zhou, S., Kuo, A., Cairns, B.R., and Crabtree, G.R. 1996b. Diversity and specialization of mammalian SWI/SNF complexes. Genes \& Dev. 10: 2117-2130.

Wang., W., Chi, T., Xue, Y., Zhou, S., and Kuo, A. 1998. Architectural DNA binding by a high mobility group/kinesin like subunit in mammalian SWI/SNF related complexes. Proc. Natl. Acad. Sci. USA 95: 492-498.

Whitehouse, I., Flaus, A., Cairns, B.R., White, M.F., Workman, J.L., and Owen-Hughes, T. 1999. Nucleosome mobilization catalysed by the yeast SWI/SNF complex. Nature 400: 784787.

Wolffe, A.P., Jones, P.L., and Wade, P.A. 1999. DNA demethylation. Proc. Natl. Acad. Sci. USA 96: 5894-5896.

Xue, Y., Wong, J., Moreno, G.T., Young, M.K., Côté, J., and Wang, W. 1998. NURD, a novel complex with both ATPdependent chromatin-remodeling and histone deacetylase activities. Mol. Cell 2: 851-861.

Zhang, Y., Iratni, R., Erdjument-Bromage, H., Tempst, P., and Reinberg, D. 1997. Histone deacetylases and SAP18, a novel polypeptide, are components of a human Sin 3 complex. Cell 89: 357-364.

Zhang, Y., LeRoy, G., Seelig, H.P., Lane, W.S., and Reinberg, D. 1998a. The dermatomyositis-specific autoantigen Mi2 is a component of a complex containing histone deacetylase and nucleosome remodeling activities. Cell 95: 279-289.

Zhang, Y., Sun, Z.-W., Iratni, R., Erdjument-Bromage, H., Tempst, P., Hampsey, M., and Reinberg, D. 1998b. SAP30, a novel protein conserved between human and yeast, is a component of a histone deacetylase complex. Cell 1: 10211031.

Zhang, H.S., Gavin, M., Dahiya, A., Postigo, A.A., Ma, D., Luo, R.X., Harbour, J.W., and Dean, D.C. 2000. Exit from G1 and $\mathrm{S}$ phase of the cell cycle is regulated by repressor complexes containing HDAC-Rb-hSWI/SNF and Rb-hSWI/SNF. Cell 101: 79-89. 


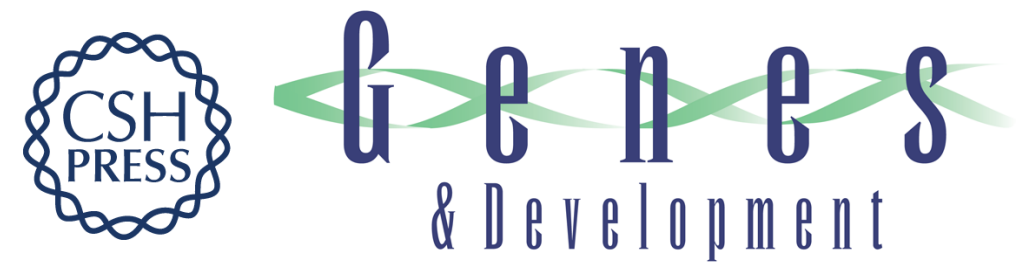

\section{Purification and characterization of mSin3A-containing Brg1 and $\mathrm{hBrm}$ chromatin remodeling complexes}

Saïd Sif, Andrew J. Saurin, Anthony N. Imbalzano, et al.

Genes Dev. 2001, 15:

Access the most recent version at doi:10.1101/gad.872801

$\begin{array}{ll}\text { References } & \text { This article cites } 52 \text { articles, } 16 \text { of which can be accessed free at: } \\ \text { http://genesdev.cshlp.org/content/15/5/603.full.html\#ref-list-1 }\end{array}$

License

Email Alerting Receive free email alerts when new articles cite this article - sign up in the box at the top Service right corner of the article or click here.

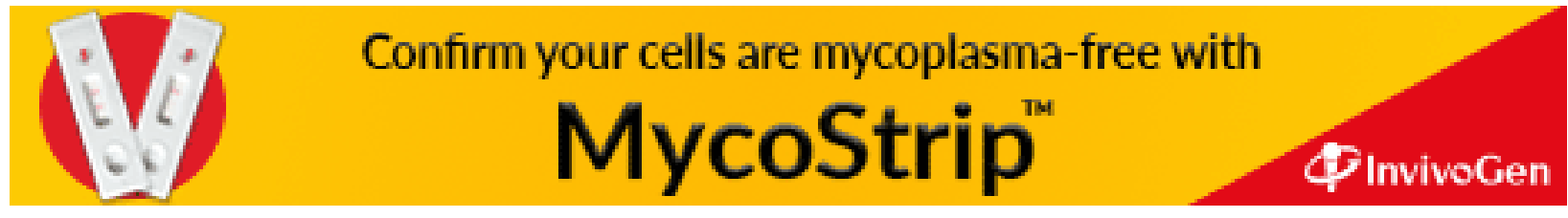

